\title{
Dry period plane of energy: Effects on glucose tolerance in transition dairy cows
}

\author{
S. Mann, ${ }^{*}$ F. A. Leal Yepes, $†$ M. Duplessis, $\ddagger^{1}$ J. J. Wakshlag,§ T. R. Overton,† B. P. Cummings,\# \\ and D. V. Nydam*2 \\ *Department of Population Medicine and Diagnostic Sciences, and \\ †Department of Animal Science, Cornell University, Ithaca, NY 14853 \\ ‡Département des sciences animales, Université Laval, Québec, G1V 0A6, Canada \\ $\S$ Department of Clinical Sciences, and \\ \#Department of Biomedical Sciences, College of Veterinary Medicine, Cornell University, Ithaca, NY 14853
}

\begin{abstract}
Overfeeding energy in the dry period can affect glucose metabolism and the energy balance of transition dairy cows with potential detrimental effects on the ability to successfully adapt to early lactation. The objectives of this study were to investigate the effect of different dry cow feeding strategies on glucose tolerance and on resting concentrations of blood glucose, glucagon, insulin, nonesterified fatty acids (NEFA), and $\beta$-hydroxybutyrate (BHB) in the peripartum period. Cows entering second or greater lactation were enrolled at dry-off ( $57 \mathrm{~d}$ before expected parturition) into 1 of 3 treatment groups following a randomized block design: cows that received a total mixed ration (TMR) formulated to meet but not exceed energy requirements during the dry period ( $\mathrm{n}=28$, controlled energy); cows that received a TMR supplying approximately $150 \%$ of energy requirements during the dry period $(\mathrm{n}=28$, high energy); and cows that were fed the same diet as the controlled energy group for the first $28 \mathrm{~d}$, after which the TMR was formulated to supply approximately $125 \%$ of energy requirements until calving $(\mathrm{n}=$ 28 , intermediate energy). Intravenous glucose tolerance tests (IVGTT) with rapid administration of $0.25 \mathrm{~g}$ of glucose $/ \mathrm{kg}$ of body weight were performed 28 and 10 $\mathrm{d}$ before expected parturition, as well as at 4 and $21 \mathrm{~d}$ after calving. Area under the curve for insulin and glucose, maximal concentration and time to half-maximal concentration of insulin and glucose, and clearance rates were calculated. Insulin resistance (IR) indices were calculated from baseline samples obtained during
\end{abstract}

Received June 3, 2015.

Accepted August 25, 2015.

${ }^{1}$ Current address: Valacta, Ste-Anne-de-Bellevue, Québec, H9X 3R4, Canada.

${ }^{2}$ Corresponding author: dvn2@cornell.edu
IVGTT and Spearman rank correlations determined between IVGTT parameters and IR indices. Treatment did not affect IVGTT parameters at any of the 4 time points. Correlation between IR indices and IVGTT parameters was generally poor. Overfeeding cows energy in excess of predicted requirements by approximately $50 \%$ during the entire dry period resulted in decreased postpartum basal plasma glucose and insulin, as well as increased glucagon, BHB, and NEFA concentrations after calving compared with cows fed a controlled energy diet during the dry period. In conclusion, overfeeding energy during the entire dry period or close-up period alone did not affect glucose tolerance as assessed by IVGTT but energy uptake during the dry period was associated with changes in peripartal resting concentrations of glucose, as well as postpartum insulin, glucagon, NEFA, and BHB concentrations.

Key words: dairy cow, transition period, energy, glucose, insulin

\section{INTRODUCTION}

The transition period represents a metabolic challenge to dairy cows because of the rapid increase of required nutrients, particularly for milk production. Excessive negative energy balance and hyperketonemia (defined as a blood concentration of $\mathrm{BHB} \geq 1.2 \mathrm{mmol} / \mathrm{L}$ ) in the postpartum period are associated with detrimental effects on health and productivity of dairy cows (Duffield et al., 2009; McArt et al., 2013b). Feeding of high energy diets during the dry period increases the degree of lipid mobilization and ketogenesis postpartum (Dann et al., 2006; Janovick et al., 2011; Mann et al., 2015). Several studies have attempted to elucidate the cause of this postpartum effect on ketogenesis in dairy cows overfed energy prepartum.

Schoenberg and colleagues (Schoenberg and Overton, 2011; Schoenberg et al., 2012) investigated how plane of nutrition affected the response of dry cows to a glucose 
challenge in 2 experiments. In these experiments, cows were fed either approximately 90 or $160 \%$, or 120 and $170 \%$ of predicted energy requirements during the dry period. Diet had no effect on the insulin response in both studies, but cows fed $90 \%$ of energy requirements tended to have higher glucose area under the curve, decreased glucose clearance, and greater nonesterified fatty acids (NEFA) response compared with overfed cows. However, no measurements were taken postpartum, including glucose tolerance tests. Holtenius et al. (2003) found a numerically higher insulin peak and higher glucose clearance prepartum, whereas glucose clearance was reduced postpartum following a glucose challenge in cows overfed energy during the dry period compared with cows fed a lower energy diet. They hypothesized that the observed postpartum changes are evidence of a greater degree of insulin resistance (IR) in cows overfed energy during the dry period, leading to more lipolysis and higher blood NEFA concentration. However, sample size was relatively small and different genetic selection lines were used.

Several studies have aimed to describe how overfeeding in the dry period affects resting concentrations of insulin and glucose in the peripartum period. Overfeeding energy during the far-off and close-up dry period (Dann et al., 2006) and during the entire dry period (Holtenius et al., 2003; Douglas et al., 2006; Janovick et al., 2011) was associated with increased insulin concentrations prepartum compared with controlled or restricted fed cows. Overfeeding during the closeup period (Dann et al., 2006) or the whole dry period (Douglas et al., 2006) resulted in higher prepartum glucose concentrations compared with cows fed restricted energy. Cows fed a controlled energy diet during the whole dry period tended to have greater insulin concentrations postpartum compared with overfed cows (Janovick et al., 2011). However, other studies showed no effect of overfeeding during the dry period on peripartal plasma glucose, glucagon, and insulin (Selim et al., 2015) or postpartal glucose and insulin concentrations (Khan et al., 2014; Schulz et al., 2014). In light of the differences found in these studies, evidence is lacking to assess whether overfeeding during the entire dry period or during close-up alone leads to peripartal changes in glucose disposal, glucose availability, or both. Because excess energy intake affects insulin sensitivity in humans (Capurso and Capurso, 2012; Johnson and Olefsky, 2013), changes in resting concentrations of insulin as well as insulin response to a glucose challenge and glucose clearance are also of interest in this context in the bovine species.

Our objective was therefore to investigate the effect of different dry period planes of energy on glucose disposal by repeated intravenous glucose tolerance test in periparturient dairy cows and to evaluate the effect on resting concentrations of blood glucose, insulin, and glucagon as well as NEFA and BHB.

\section{MATERIALS AND METHODS}

\section{Animals, Feeding, and Management}

All procedures were approved by the Cornell University Institutional Animal Care and Use Committee. A detailed description of animals, feeding, and management was reported previously (Mann et al., 2015). In brief, Holstein cows $(n=84)$ entering second or greater lactation from the herd at the Cornell Teaching and Research Center were enrolled between September 2012 and April 2013. All animals were housed in individual sawdust-bedded tiestalls equipped with individual feed bins. Cows were allocated to 1 of 3 dry-period dietary treatment groups using a randomized block design to control for time-dependent variation with 3 treatments in 28 blocks on the day of dry off (approximately 57 $\mathrm{d}$ before expected parturition). Blocking was based on expected calving date. Random sequence of allocation within the block was determined with a random number generator (Research Randomizer v.4.0; Urbaniak and Plous, 2012). Groups did not differ in BCS (on a scale of 1.0 to 5.0 according to Edmonson et al., 1989) of animals at enrollment or in the distribution of parity (Mann et al., 2015). Animals were enrolled in 1 of 3 feeding groups: a TMR formulated to meet $100 \%$ of energy requirements at predicted ad libitum intake (controlled energy, C); a TMR formulated to supply $150 \%$ of energy requirements (high energy, $\mathbf{H}$ ); and an intermediate group that received the same TMR as group C for the first $28 \mathrm{~d}$ after dry off and a TMR formulated to supply $125 \%$ of energy requirements from d 28 before expected parturition until calving (intermediate energy, I, representing a 50:50 blend of both $\mathrm{C}$ and $\mathrm{H}$ diets). On a DM basis, conventional corn silage accounted for $28.5,42.2$, and $55.9 \%$ in diets $\mathrm{C}$, I, and $\mathrm{H}$, respectively, and wheat straw was included at 35.6, 24.0, and $12.4 \%$ of DM in groups $\mathrm{C}$, I, and $\mathrm{H}$, respectively. All cows received the same fresh cow TMR from the onset of lactation until the end of the study period (42 DIM). Milk yield was measured at every milking (0900 and 2100 h). Rations were formulated using the Cornell Net Carbohydrate and Protein System software (CNCPS version 6.1; Cornell University, Ithaca, NY). Samples of all TMR were taken weekly and analyzed based on a monthly composite at a commercial laboratory with wet chemistry methods (Dairy One Cooperative Inc., Ithaca, NY). All diets were offered ad libitum fed once daily at $0900 \mathrm{~h}$, and amounts fed were adjusted to allow for a minimum of $5 \%$ refusals. 


\section{Intravenous Glucose Tolerance Test}

Intravenous glucose tolerance tests (IVGTT) were performed on all cows, targeting 28 and $10 \mathrm{~d}$ before expected parturition and 4 and $21 \mathrm{~d}$ postpartum. On sampling days, refusals were removed at $0700 \mathrm{~h}$ and cows were kept in box stalls after morning milking, which was completed at $1000 \mathrm{~h}$. A 14-gauge $\times 140$-mm catheter with a $305 \mathrm{~mL} / \mathrm{min}$ capacity (Abbocath-T, Hospira, Sligo, Ireland) was placed in the jugular vein. A $15-\times 10-\mathrm{cm}$ area was clipped and scrubbed with povidone iodine and $70 \%$ ethanol, and $2 \mathrm{~mL}$ of $2 \%$ lidocaine (Vet One, Boise, ID) was injected subcutaneously. The area was scrubbed again and the catheter was placed approximately $10 \mathrm{~min}$ later and flushed with $10 \mathrm{IU}$ of heparin $/ \mathrm{mL}$ of a $0.9 \%$ sterile saline solution (heparin: Sagent Pharmaceuticals, Schaumburg, IL, saline solution: Abbott Animal Health, Abbott Park, IL). Cows were allowed to rest with access to water, but not feed, until the IVGTT was initiated.

Baseline samples were taken at 15 and 5 min before and $0,5,10,15,20,25,30,45,60,90$, and $120 \mathrm{~min}$ after completion of an intravenous bolus infusion of $0.25 \mathrm{~g}$ of glucose $/ \mathrm{kg}$ of BW $(50 \%$ dextrose solution, Vet One) into evacuated tubes (Becton Dickinson Vacutainer Systems, Franklin Lakes, NJ) with 158 US Pharmacopeia (USP) units of sodium heparin. The glucose solution was heated before use in a water bath to body temperature and infusion completed within approximately 2 to $3 \mathrm{~min}$ through a large bore infusion set (Jorgensen Laboratories, Loveland, CA). All samples were immediately placed on ice and centrifuged within $30 \mathrm{~min}$ at $2,800 \times g$ for $20 \mathrm{~min}$, and plasma samples were stored as $1-\mathrm{mL}$ aliquots in $1.7-\mathrm{mL}$ microcentrifuge tubes (VWR, Radnor, PA) to prevent multiple freezethaw cycles after snap freezing with liquid nitrogen. Samples were stored at $-20^{\circ} \mathrm{C}$ until analysis.

\section{Analysis of IVGTT Blood Samples}

Plasma glucose (PGO enzyme preparation, Sigma Aldrich, St. Louis, MO) and NEFA (HR Series NEFAHR (2); Wako Life Sciences, Mountain View, CA) concentrations were measured by colorimetric assay from all baseline samples. In addition, NEFA concentration was determined for all samples of each IVGTT at d 10 before and d 4 after parturition for animals in 19 out of 28 blocks only, and plasma concentration of glucose was determined for all IVGTT samples at all time points.

Plasma concentration of insulin was determined for all time points of each IVGTT for animals in 19 out of 28 blocks using a RIA kit (PI-12K Porcine Insulin RIA, EMD Millipore Corp., Billerica, MA). The concentration of BHB was determined for all baseline samples using a handheld device (Precision Xtra meter, Abbott Diabetes Care Inc., Alameda, CA) in whole blood immediately after obtaining the sample. Plasma glucagon concentration was determined for all baseline samples of IVGTT from animals in 19 out of 28 enrollment blocks using a RIA kit (Glucagon RIA kit, Millipore).

On sampling days, subcutaneous and muscle biopsies were taken from the area of the paralumbar fossa (data not presented), and all animals received $2.2 \mathrm{mg} /$ $\mathrm{kg}$ flunixin meglumine (Prevail, VetOne) i.v. for minor pain mitigation.

\section{Weekly Blood Sampling}

Blood sampling in the peripartum period is described in detail in Mann et al. (2015). In brief, blood samples $(10 \mathrm{~mL})$ were taken 3 times per week before feeding (between 0600 and $0730 \mathrm{~h}$ ) from the coccygeal vein or artery, placed on ice, separated within $1 \mathrm{~h}$ by centrifugation at $2,800 \times g$ for $20 \mathrm{~min}$ at $4^{\circ} \mathrm{C}$, snap-frozen in liquid $\mathrm{N}_{2}$, and stored at $-20^{\circ} \mathrm{C}$. All samples were frozen in 4 aliquots to prevent multiple freeze-thaw cycles. An animal was considered as hyperketonemic when BHB concentrations obtained during morning sampling reached $1.2 \mathrm{mmol} / \mathrm{L}$ (McArt et al., 2013a). Cows exhibiting a concentration of BHB $\geq 2.5 \mathrm{mmol} / \mathrm{L}$ were treated with $250 \mathrm{~mL}$ of a $50 \%$ dextrose solution (Dextrose $50 \%$ inj, VetOne, i.v.) on 2 consecutive days as well as $300 \mathrm{~mL}$ (approximately $310 \mathrm{~g}$ ) of propylene glycol orally for 5 consecutive days starting on the day of diagnosis. Subsequent episodes after this initial treatment were treated with another 5 -d course of oral propylene glycol alone and this was repeated until BHB concentrations were determined to be $<2.5 \mathrm{mmol} / \mathrm{L}$. Animals that had at least one episode of hyperketonemia within the first 21 DIM were considered as positive cows (HYK) for statistical analysis. In addition to the described analysis of IVGTT baseline samples, glucose, glucagon, and insulin concentrations were determined in all weekly plasma samples from $7 \mathrm{~d}$ before until $7 \mathrm{~d}$ after parturition. Concentrations of BHB were determined 3 times per week in whole blood from 3 wk before until 3 wk after parturition, and NEFA concentrations were determined at the same time points in serum.

\section{Analytical Approach: Molar Insulin:Glucagon Ratio and Surrogate Indices}

The molar ratio of insulin and glucagon was computed after conversion of insulin from microunits per milliliter to picomoles per liter by multiplication by a factor 6.0 (Heinemann, 2010), and for glucagon from picograms per milliliter to picomoles per liter by multiplying by the factor 0.287 (Banarer et al., 2002). Seven 
baseline samples $(1,2$, and 4 in groups $\mathrm{C}$, I and $\mathrm{H}$, respectively) had undetectable concentrations of insulin as determined by RIA; for those samples, a value of 0 was used and samples were omitted from calculation of molar insulin:glucagon ratio (IG) ratio as well as surrogate index calculations.

The IR indices homeostasis model of insulin resistance (HOMA-IR) according to Muniyappa et al. (2008), quantitative insulin sensitivity check index (QUICKI) according to Katz et al. (2000), revised QUICKI (RQUICKI) according to Perseghin et al. (2001), and revised QUICKI including BHB (RQUICKI $\left.\mathbf{B H B}_{\mathrm{BHB}}\right)$ according to Balogh et al. (2008) were calculated as follows:

$$
\begin{gathered}
\text { HOMA-IR }=\{[\text { glucose }(\mathrm{mmol} / \mathrm{L}) \\
\times \text { insulin }(\mu \mathrm{U} / \mathrm{mL})] / 22.5\}, \\
\text { QUICKI }=\{1 /[\log \text { insulin }(\mu \mathrm{U} / \mathrm{mL}) \\
+\log \text { glucose }(\mathrm{mg} / \mathrm{dL})]\}, \\
\text { RQUICKI }=\{1 /[\log \text { glucose }(\mathrm{mg} / \mathrm{dL}) \\
+\log \text { insulin }(\mu \mathrm{U} / \mathrm{mL})+\log \mathrm{NEFA}(\mathrm{mmol} / \mathrm{L})]\}, \\
\text { RQUICKI }_{\mathrm{BHB}}=\{1 /[\log \text { glucose }(\mathrm{mg} / \mathrm{dL}) \\
+\log \text { insulin }(\mu \mathrm{U} / \mathrm{mL})+\log \mathrm{NEFA}(\mathrm{mmol} / \mathrm{L}) \\
+\log \mathrm{BHB}(\mathrm{mmol} / \mathrm{L})]\} .
\end{gathered}
$$

Glucose clearance rate (CR) was calculated according to the method described by Kerestes et al. (2009):

$$
\text { Glucose } \mathrm{CR}=[(\ln \text { glucose at time point } 0
$$

$-\ln$ glucose at time point 60$) / 60] \times 100=\% / \min$.

Insulin CR was calculated as follows:

Insulin $\mathrm{CR}=[(\mathrm{ln}$ insulin at peak time point

- $\ln$ insulin at time point 60$) / 60$ - peak time point]

$$
\times 100=\% / \min .
$$

\section{Statistical Analysis}

The primary outcome of this study was the description of measurements obtained during IVGTT and included resting blood concentration as well as glucose, insulin and NEFA response to the glucose challenge. Values from both baseline samples of each IVGTT were averaged to generate a single baseline value. Area under the curve (AUC) for insulin, glucose, and NEFA concentrations was calculated in SAS (version 9.3; SAS Institute Inc., Cary, NC) as the positive incremental area adjusting for baseline according to the method described by Cardoso et al. (2011). Mixed-effects ANOVA were carried out with PROC MIXED with the independent variables treatment group and HYK and dependent variables of IVGTT parameters. The interaction of treatment and HYK was tested for every ANOVA and included in the model if $P<0.05$. Enrollment block was included as a random effect. Experiment-wise error rate for all ANOVA was corrected with Tukey's test, and reported $P$-values for comparisons among groups represent those corrected for multiple comparisons. Continuous data were tested for normality. Data for the outcome parameters IG ratio, insulin, and BHB concentrations on d 4 postpartum, BHB concentrations on d 28 prepartum and d 21 postpartum, maximal glucose concentration, time to half-maximal glucose concentration, and AUC for glucose and insulin were log-transformed to satisfy this assumption. Results of corresponding least squares means of log-transformed data were subsequently back transformed and are reported as geometric means and 95\% CI; results of untransformed data are reported as mean and 95\% CI. A chi-squared test was performed with Proc FREQ for parity differences within treatment. The assumption of homoscedasticity was tested for each ANOVA with Levene's test. In cases that this assumption was violated, Welch's test was performed. The correlation between BHB and glucose concentration at $\mathrm{d} 4$ postpartum was evaluated using Pearson correlation.

For the analysis of secondary outcomes, repeatedmeasures ANOVA was performed for resting concentrations of glucose, glucagon, insulin, NEFA, BHB, and IG ratio from $7 \mathrm{~d}$ prepartum to $7 \mathrm{~d}$ postpartum in cows with and without hyperketonemia using PROC MIXED in SAS. Three covariance structures were tested (autoregressive 1, unstructured, compound symmetry) and the one yielding the smallest Akaike information criterion was chosen. Fixed effect was HYK group and the REPEATED statement was time. The interaction of HYK status and time was forced into every model. When results of the ANOVA analysis yielded a $P$-value of $\leq 0.05$, Tukey's post hoc test was used for comparison of means across all groups to control experiment-wise error rate. Normality of residuals was tested after each model fit. Another secondary outcome was the correlation between the IR indices and AUC as well as curve parameters (time to maximal concentration, time to half-maximal concentration, and maximal concentration), which were tested for each sampling day using the Spearman rho correlation. Results were reported if Spearman $\rho>0.50$. The correlation between IR indices 
on d 4 postpartum calculated from morning samples with those calculated from IVGTT baseline parameters was also analyzed using Spearman correlation.

Descriptive statistical analyses using one-way ANOVA were carried out using Proc GLM for treatment differences in BW at enrollment, BCS, dry period length, milk production, sampling day relative to calving, and IVGTT glucose dose. For the effect of time, corresponding ANOVA were carried out to analyze the differences in least squares means for IVGTT parameters using period and group as fixed effects and including enrollment block as random effect. Results are presented as means or geometric means and $95 \%$ CI unless otherwise stated.

\section{RESULTS AND DISCUSSION}

Cows were dry for an average of $55.5 \mathrm{~d}$ (C: $56.5 \pm$ 3.1 , I: $55.0 \pm 5.4, \mathrm{H}: 55.2 \pm 4.3 ; P=0.4)$. The average BW at enrollment was $672(657-686) \mathrm{kg}$ and did not differ between groups $(P>0.43)$. A BCS score of 3.0 was predominant at dry-off $(\mathrm{n}=40,48 \%)$ with 13 animals at BCS $2.75(15 \%)$ and 27 animals at BCS of 3.25 or $3.50(32 \%)$; the remaining 4 animals $(5 \%)$ had a BCS of $3.75(\mathrm{n}=3)$ or $4.0(\mathrm{n}=1)$. On average, cows in group $\mathrm{H}$ gained an additional (mean with $95 \% \mathrm{CI}$ in parentheses) $0.27(0.18-0.36)$ point in BCS score compared with group $\mathrm{C}[0.15(0.07-0.24) ; P=0.15)$, and group I [0.11 (0.02-0.19); $P=0.03]$. However, it has to be taken into account that BCS may lack sensitivity for the detection of differences in visceral fat mass, as recently described (Drackley et al., 2014), and that the small difference in BCS between the groups might result in an underestimation of true differences in adipose tissue gain. In fact, weight gain in the dry period was also highest in group H [90.4 (82.7-98.1) kg] compared with group C [72.1 (64.3-79.8) kg; $P=0.004]$ and group I $[71.0(63.3-78.8) \mathrm{kg} ; P=0.002]$. The majority of cows ( $\mathrm{n}=51$ ) were entering parity 2 , and 33 animals were entering parity 3 and greater; the distribution of parity was not different between groups $(P=0.34)$. Selected items from the chemical analysis of rations and predicted MP supplies for pre- and postpartum diets are presented in Table 1. The complete list of ingredients of each diet, wet chemistry analysis results, as well as milk production and composition were previously described (Mann et al., 2015). Overall, the averages of milk yield in the first 2 wk of lactation [C: $36.2(33.8-38.6)$, I: $35.9(33.6-38.2)$, H: $37.0(34.7-39.3) \mathrm{kg} ; P=0.80]$ as well as wk 3 and 4 of lactation [C: $47.7(45.2-50.2)$, I: 46.2 (43.8-48.7), H: 45.8 (43.4-48.2) kg; $P=0.53]$ were not different among dietary treatment groups. Cows that became hyperketonemic in the first 21 DIM $(\mathrm{n}=$ $29)$ and those that did not $(\mathrm{n}=55)$ had similar milk production in the first $2 \mathrm{wk}[37.0(34.6-39.5)$ vs. 35.6 (33.9-37.4) kg; $P=0.35]$ and in wk 3 and 4 after calving [46.9 (44.5-49.4) vs. $46.0(44.2-47.8) \mathrm{kg} ; P=0.54]$. Intra- and interassay coefficients of variation (CV) for glucose, NEFA, insulin, and glucagon measurements were 2.2 and $6.4 \%, 3.1$ and $8.2 \%, 6.9$ and $5.7 \%$, and 4.6 and $12.9 \%$, respectively.

\section{Glucose and Insulin Response During IVGTT}

The primary objective of this study was to evaluate the effect of different dry period planes of energy on glucose tolerance in peripartum dairy cows. The dose of glucose administered during the IVGTT was smaller than the one used in a previous study (Kerestes et al., 2009), but similar to (Hove, 1978; Zachut et al., 2013), the same as (Schoenberg and Overton, 2011; Schoenberg et al., 2012), or larger than that used in other

Table 1. Analyzed composition (mean $\pm \mathrm{SD}$ ) of diets

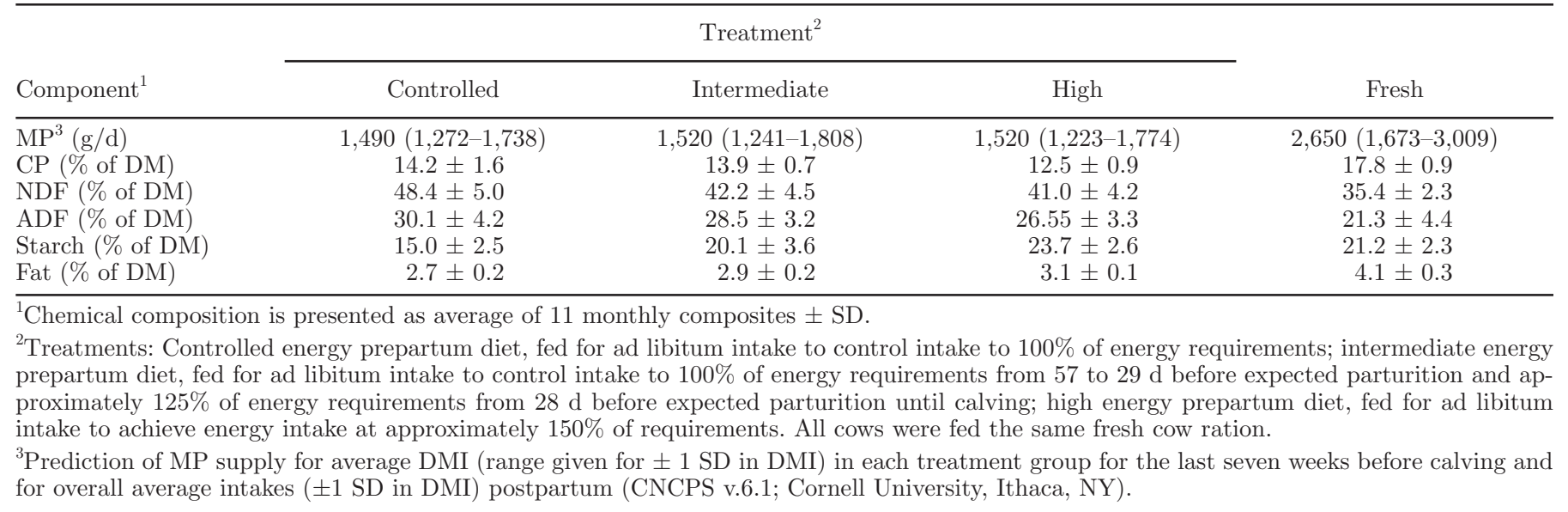


studies (Holtenius et al., 2003), which should be taken into consideration when comparing results between studies.

The mean and SD of actual sampling day for IVGTT was $26.6 \pm 4.2$ and $7.9 \pm 4.0 \mathrm{~d}$ before calving and 4.6 \pm 1.2 and $21.0 \pm 1.2 \mathrm{~d}$ postpartum. The average time point of glucose infusion was $1230 \mathrm{~h}$ (1120 to $1340 \mathrm{~h}$ ) and approximately $5 \mathrm{~h}$ after morning blood sampling and feed removal.

Figures 1 and 2 depict the mean and SD of glucose and insulin concentrations during the IVGTT carried out at the 4 different time points. Maximal concentrations of insulin and glucose, the clearance rate of both, time to half-maximal values for both analytes, and total AUC were not different among groups for any of the time points (Table 2). Time to maximal insulin concentration was also not different (Table 2). The findings of our study are similar to those of a previous study by Schoenberg and Overton (2011), where no differences were detected in IVGTT measurements of insulin and glucose between dry-period energy treatment groups during late gestation. In a second study, RQUICKI, IVGTT parameters, and insulin sensitivity, as assessed by the hyperinsulinemic-euglycemic clamp tests, did not differ between treatment groups of varying energy levels in the dry period (Schoenberg et al., 2012). Together, these studies and the current experiment suggest that overfeeding during the dry period does not alter the ability of dairy cows to respond to a glucose challenge compared with cows being fed a controlled energy diet.

Several measurements obtained from IVGTT were different between the 4 different sampling time points of the pre- and postpartum period and when controlling for differences between treatment groups. Glucose clearance was highest at $21 \mathrm{~d}$ postpartum [2.05 $(1.97-2.11) \% / \mathrm{min}]$, followed by rates on d 4 postpartum [1.85 (1.78-1.93)\%/min], and both were different compared with both prepartum sampling time points [28 d prepartum: 1.51 (1.44-1.59); $10 \mathrm{~d}$ prepartum: $1.61(1.54-1.69) \% / \mathrm{min} ; P<0.0001]$. The glucose CR between $\mathrm{d} 21$ and 4 postpartum was also different $(P<$ 0.002). Maximum concentrations for glucose at 28 and $10 \mathrm{~d}$ prepartum [256 (247-266) and $266(257-276) \mathrm{mg} /$ $\mathrm{dL}$, respectively] were higher than those on $\mathrm{d} 4$ and 21 postpartum [207 (197-216) and $221(212-230) \mathrm{mg} / \mathrm{dL}$; $P<0.0001]$.

The increased glucose clearance is likely linked to the onset of lactation (Debras et al., 1989). For every kilogram of milk produced, $72 \mathrm{~g}$ of glucose is needed (Kronfeld, 1982). This higher basal glucose turnover in lactating cows has to be taken into account when comparing lactating cows to dry cows (De Koster and Opsomer, 2013), and this limits comparability of IVGTT findings between nonlactating and lactating animals. As opposed to previously reported findings (Kerestes et al., 2009), we saw both increased glucose and insulin clearance in cows postpartum. Numerically lower glucose CR in animals fed higher energy diets postpartum were observed previously and interpreted as increased IR (Holtenius et al., 2003). Discrepancies in study design, sample size, and genetics could be variables that account for the differences observed between that study and the current one.

Insulin clearance was highest at 21 and $4 \mathrm{~d}$ postpartum [21 d postpartum: 4.35 (4.03-4.66); 4 d postpartum: $4.13(3.81-4.45) \% / \mathrm{min}]$ compared with both prepartum time points [28 d prepartum: $2.16(1.85-2.47)$; 10 d prepartum: $2.23(1.92-2.53) \% / \mathrm{min} ; P<0.0001]$. Maximum concentration of insulin was 160 (144-178), $112(101-124), 50(45-55)$, and $67(60-74) \mu \mathrm{U} / \mathrm{mL}$ on d 28 and 10 prepartum and 4 and 21 d postpartum, respectively, and concentrations at all 4 time points were different from each other $(P<0.001)$.

Zachut et al. (2013) hypothesized that the higher insulin AUC to clear the same dose of glucose in the prepartum period compared with the postpartum period indicates a degree of IR in late gestation, as described by Bell (1995). Similar to our own findings, Bossaert et al. (2008) reported lower insulin AUC in lactation and attributed this to reduced insulin secretion, which could be part of the physiologic homeorhetic adaptation to early lactation. According to Malven et al. (1987), insulin uptake into the mammary gland after parturition is negligible and unlikely to play a role in the observed increase in clearance rate postpartum. Because insulin is predominantly metabolized in the liver (Ferrannini and Cobelli, 1987) and liver blood flow increases substantially with lactation, the increased insulin clearance could also be due to an increased rate of degradation (Lomax and Baird, 1983). However, peak insulin concentrations observed postpartum were greatly reduced compared with prepartum peak concentrations, and could help explain the observed changes in insulin clearance independently of changes in uptake by the mammary gland or increased metabolization rate by the liver.

\section{Effect of Dry Period Plane of Energy on NEFA Response During IVGTT}

Figure 3 shows the percentage of reduction from baseline of plasma NEFA concentrations at sampling time points d 10 prepartum and d 4 postpartum, which did not differ among treatment groups. This is in contrast to both studies by Schoenberg and colleagues (Schoenberg and Overton, 2011; Schoenberg et al., 2012). Concentrations of NEFA reached a nadir around 
45 min after glucose infusion, which is similar to findings by Zachut et al. (2013). This represents the rapid inhibition of lipolysis by insulin (Ruan and Lodish, 2003), which we observed regardless of the differences in insulin concentration from pre- to postpartum time points and regardless of the large increase in NEFA concentrations postpartum compared with prepartum. Circulating NEFA are readily removed from the bloodstream through lipid storage or uptake by the liver, as well as by the mammary gland during lactation (Pethick, 2005). The absolute changes in NEFA concentrations expressed as AUC were not different on d 10 prepartum [C: -25.8 ( -19.4 to -32.2$)$, I: -22.0 $(-15.6$ to -28.4$), \mathrm{H}:-23.5(-17.1$ to -29.9$) \mathrm{mmol} \cdot 120$ $\min / \mathrm{L} ; P=0.70]$ and d 4 postpartum $[\mathrm{C}:-62.7(-54.8$ to -70.5$)$, I: -56.7 ( -48.9 to -64.6$), \mathrm{H}:-67.6(-60.0$ to -75.5$) \mathrm{mmol} \cdot 120 \mathrm{~min} / \mathrm{L} ; P=0.15]$. The authors of a recent study investigating the effect of insulin on FA metabolism in dry dairy cows differing in body condition found that inhibition of lipolysis remains intact in overconditioned cows and lower insulin concentrations are necessary for its action on FA metabolism compared

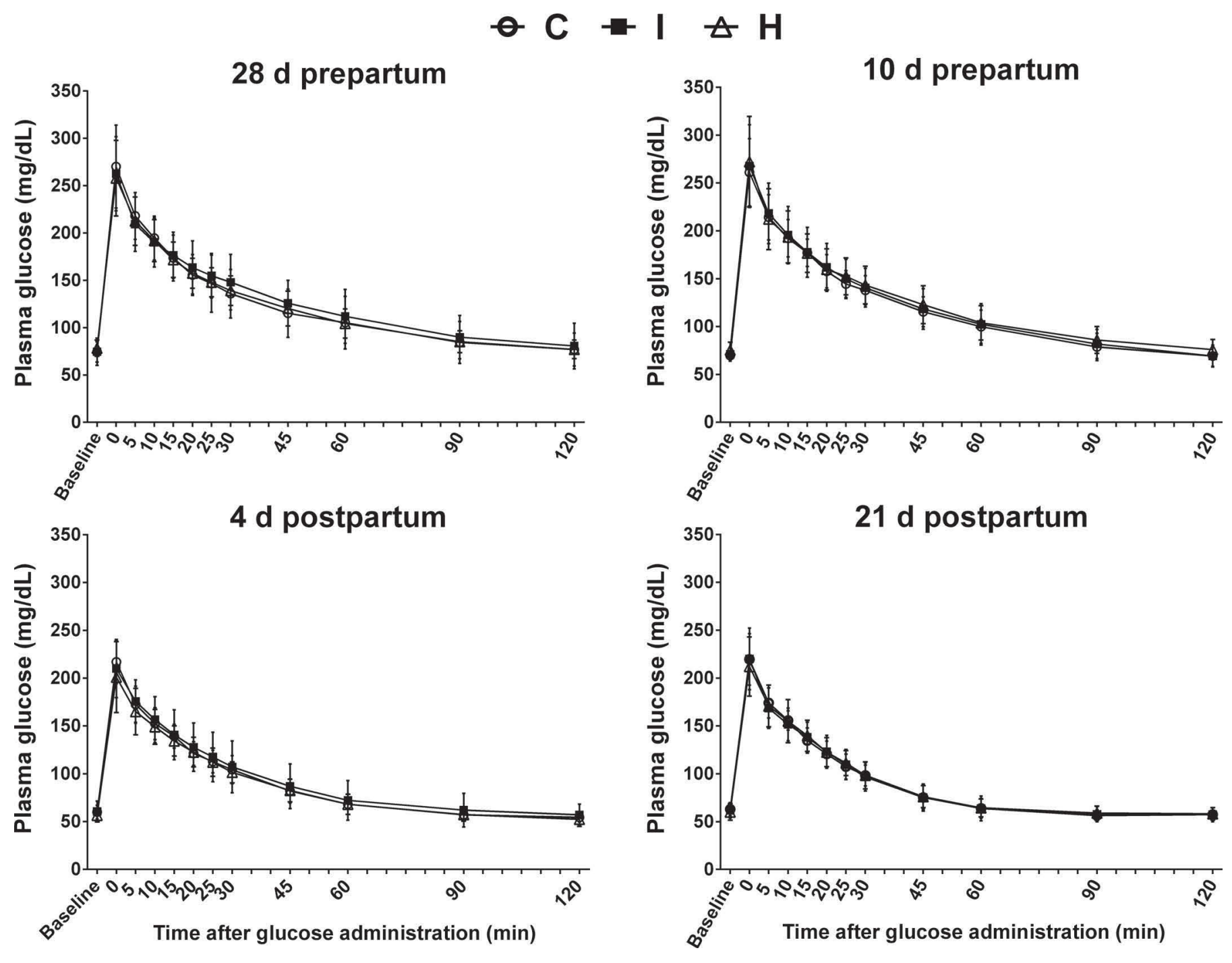

Figure 1. Mean plasma concentration of glucose $(\mathrm{mg} / \mathrm{dL})$ during intravenous glucose tolerance test (IVGTT) performed at 28 and 10 d prepartum, as well as 4 and 21 d postpartum. Error bars represent SD. Least squares means (95\% CI) of area under the curve for time points 28 and $10 \mathrm{~d}$ prepartum as well as 4 and $21 \mathrm{~d}$ postpartum were 5.7 (5.2-6.1), 5.9 (5.4-6.4), 3.7 (3.2-4.1), and 3.4 (2.9-3.8) g.120 min/dL, respectively. Baseline represents the average of samples taken 15 and $5 \mathrm{~min}$ before glucose infusion. Time point 0 represents sample taken immediately after intravenous bolus administration of $0.25 \mathrm{~g}$ of glucose per $\mathrm{kg}$ of $\mathrm{BW}$. C = controlled-energy prepartum diet, fed for ad libitum intake to control intake to $100 \%$ of energy requirements; I = intermediate-energy prepartum diet, fed for ad libitum intake to control intake to $100 \%$ of energy requirements from 57 to 29 d before expected parturition and approximately $125 \%$ of energy requirements from $28 \mathrm{~d}$ before expected parturition until calving; $\mathrm{H}=$ high-energy prepartum diet, fed for ad libitum intake to achieve energy intake at approximately $150 \%$ of requirements. Values based on 28 animals in each group. 


\section{$\theta C \rightarrow I \Delta H$}
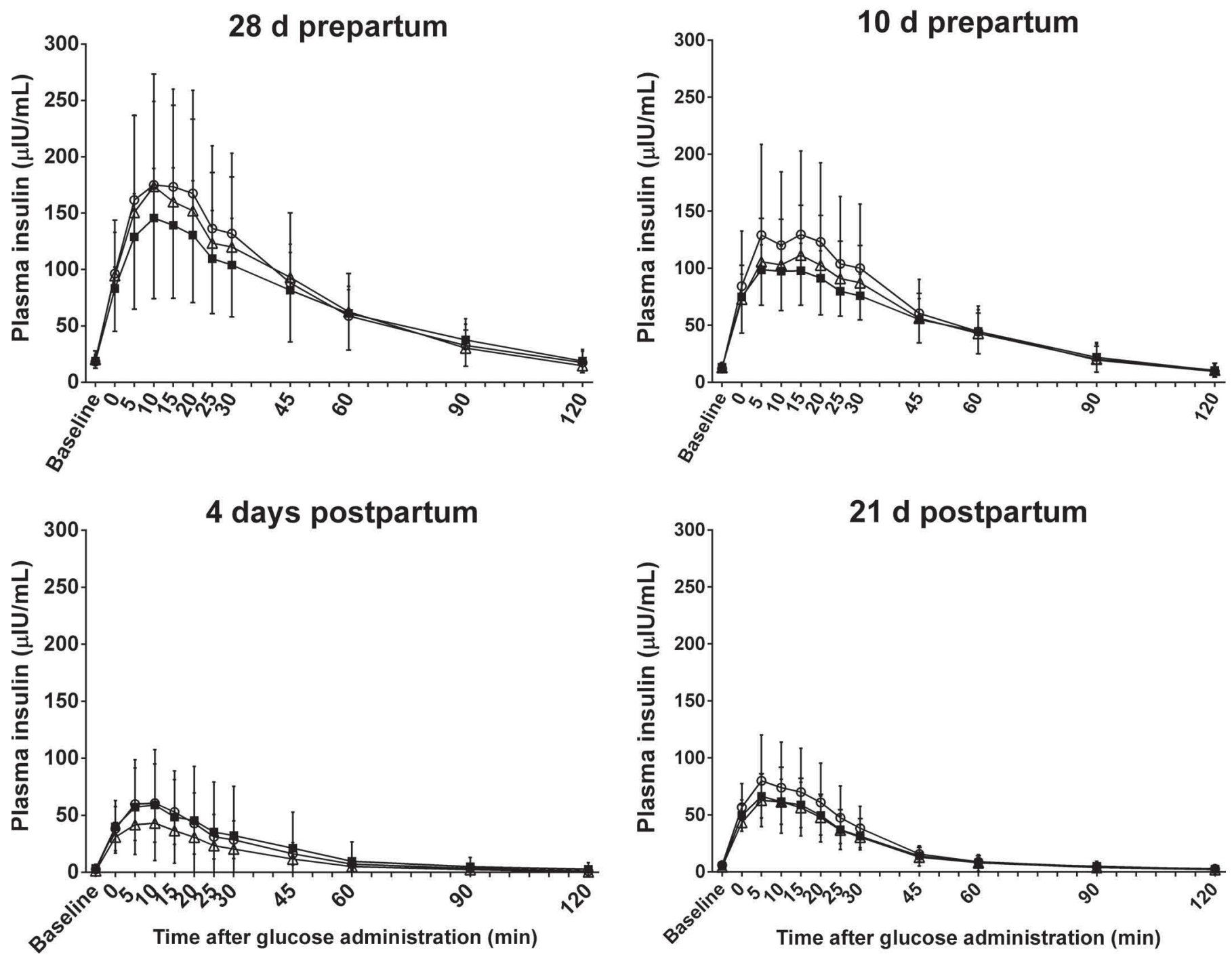

Figure 2. Mean plasma concentration of insulin $(\mu \mathrm{U} / \mathrm{mL})$ during intravenous glucose tolerance test (IVGTT) performed at 28 and $10 \mathrm{~d}$ prepartum as well as 4 and $21 \mathrm{~d}$ postpartum. Error bars represent SD. Least squares means (95\% CI) of area under the curve for time points 28 and $10 \mathrm{~d}$ prepartum as well as 4 and $21 \mathrm{~d}$ postpartum were $5.7(4.7-6.8), 4.2(3.5-5.0), 1.4(1.2-1.7)$, and $1.7(1.4-2.0) \mathrm{mU} \cdot 120 \mathrm{~min} / \mathrm{mL}$, respectively. Baseline represents the average of samples taken 15 and $5 \mathrm{~min}$ before glucose infusion. Time point 0 represents the sample taken immediately after bolus administration of intravenous $0.25 \mathrm{~g}$ of glucose per $\mathrm{kg}$ of $\mathrm{BW} . \mathrm{C}=$ controlled-energy prepartum diet, fed for ad libitum intake to control intake to $100 \%$ of energy requirements; I = intermediate-energy prepartum diet, fed for ad libitum intake to control intake to $100 \%$ of energy requirements from 57 to 29 d before expected parturition and approximately $125 \%$ of energy requirements from 28 d before expected parturition until calving; $\mathrm{H}=$ high-energy prepartum diet, fed for ad libitum intake to achieve energy intake at approximately $150 \%$ of requirements. Values were based on 19 animals in each group.

with actions on glucose metabolism (De Koster et al., 2015). The results of our study also suggest that even a lower insulin response to glucose challenge (smaller AUC, lower peak concentration) postpartum leads to a similar effect on reduction of NEFA concentration and therefore inhibition of lipolysis compared with prepartum time points. In addition, the absence of a difference between the treatment groups in the present study indicates that inhibition of lipolysis and rate of removal of NEFA were not affected by the energy level and concurrent differences in body condition and weight gain during the dry period. These results, together with the absence of differences in insulin response to a glucose challenge, can be interpreted such that the increase in $\mathrm{BCS}$ and $\mathrm{BW}$ in group $\mathrm{H}$ compared with groups $\mathrm{C}$ and I did not alter the insulin response to a glucose chal- 
Table 2. Results of mixed effects ANOVA for treatment (T) differences in intravenous glucose tolerance test parameters at 28 and $10 \mathrm{~d}$ prepartum ( -28 and -10$)$ as well as 4 and $21 \mathrm{~d}$ postpartum $(+4$ and +21$)$ for treatment groups and $\mathrm{HYK}^{2}$ status

\begin{tabular}{|c|c|c|c|c|c|c|c|c|}
\hline \multirow[b]{2}{*}{ Measurement } & \multicolumn{4}{|c|}{ Treatment $^{1}$} & \multicolumn{3}{|c|}{$\mathrm{HYK}^{2}$} & \multirow{2}{*}{$\begin{array}{c}\mathrm{T} \times \mathrm{HYK} \\
P \text {-value }\end{array}$} \\
\hline & Controlled & Intermediate & High & $P$-value & No & Yes & $P$-value & \\
\hline \multicolumn{9}{|c|}{ Maximal glucose concentration $(\mathrm{mg} / \mathrm{dL})^{3}$} \\
\hline$-28 \mathrm{~d}$ & $260(243-278)$ & $258(243-275)$ & $256(242-272)$ & 0.76 & $260(250-271)$ & $256(242-272)$ & 0.87 & 0.50 \\
\hline$-10 \mathrm{~d}$ & $259(243-276)$ & $261(246-277)$ & $269(254-284)$ & 0.54 & $268(258-279)$ & $258(244-272)$ & 0.66 & 0.61 \\
\hline$+4 \mathrm{~d}$ & $213(203-225)^{\mathrm{a}}$ & $209(199-220)^{\mathrm{b}}$ & $198(188-209)^{\mathrm{c}}$ & 0.08 & $211(204-219)$ & $203(193-213)$ & 0.20 & 0.10 \\
\hline$+21 \mathrm{~d}$ & $220(208-233)$ & $217(206-228)$ & $210(200-221)$ & 0.58 & $219(211-227)$ & $212(202-223)$ & 0.36 & 0.32 \\
\hline \multicolumn{9}{|c|}{ Time (min) to half-maximal glucose concentration ${ }^{3}$} \\
\hline$-28 \mathrm{~d}$ & $34.7(28.5-42.3)$ & $42.5(35.6-50.8)$ & $37.4(31.6-44.4)$ & 0.10 & $36.7(32.4-41.5)$ & $39.5(33.3-47.0)$ & 0.56 & 0.51 \\
\hline$-10 \mathrm{~d}$ & $36.2(30.9-42.4)$ & $35.2(30.5-40.5)$ & $35.4(30.9-40.6)$ & 0.95 & $33.5(30.3-36.9)$ & $37.9(33.1-43.5)$ & 0.15 & 0.72 \\
\hline$+4 \mathrm{~d}$ & $27.4(24.4-30.7)$ & $29.7(26.5-33.2)$ & $31.8(28.5-35.5)$ & 0.20 & $28.3(26.2-30.6)$ & $30.8(27.6-34.4)$ & 0.22 & $0.02^{4}$ \\
\hline$+21 \mathrm{~d}$ & $24.3(21.5-26.7)$ & $24.1(22.1-26.7)$ & $27.4(25.0-30.0)$ & 0.10 & $25.1(23.4-26.8)$ & $25.3(23.1-27.8)$ & 0.77 & 0.63 \\
\hline \multicolumn{9}{|c|}{ Glucose clearance rate $(\% / \mathrm{min})$} \\
\hline$-28 \mathrm{~d}$ & $1.6(1.5-1.8)$ & $1.5(1.3-1.6)$ & $1.5(1.4-1.7)$ & 0.20 & $1.5(1.4-1.6)$ & $1.5(1.4-1.7)$ & 0.76 & 0.54 \\
\hline$-10 \mathrm{~d}$ & $1.6(1.5-1.7)$ & $1.6(1.5-1.7)$ & $1.6(1.5-1.7)$ & 0.99 & $1.6(1.5-1.7)$ & $1.6(1.5-1.7)$ & 0.77 & 0.87 \\
\hline$+4 \mathrm{~d}$ & $1.9(1.7-1.9)$ & $1.8(1.7-1.9)$ & $1.8(1.7-1.9)$ & 0.30 & $1.9(1.8-2.0)$ & $1.8(1.7-1.9)$ & 0.17 & 0.26 \\
\hline$+21 \mathrm{~d}$ & $2.1(1.9-2.2)$ & $2.1(2.0-2.2)$ & $2.0(1.9-2.1)$ & 0.47 & $2.1(2.0-2.1)$ & $2.0(1.9-2.2)$ & 0.91 & 0.75 \\
\hline \multicolumn{9}{|c|}{ Glucose AUC (g. $120 \mathrm{~min} / \mathrm{dL})^{3}$} \\
\hline$-28 \mathrm{~d}$ & $5.60(5.05-6.21)^{\mathrm{ab}}$ & $6.21(5.64-6.83)^{\mathrm{a}}$ & $5.33(4.87-5.84)^{\mathrm{b}}$ & 0.07 & $5.56(5.21-5.94)$ & $5.85(5.34-6.40)$ & 0.36 & 0.93 \\
\hline$-10 \mathrm{~d}$ & $6.01(5.45-6.64)$ & $5.94(5.42-6.51)$ & $5.83(5.35-6.36)$ & 0.83 & $5.94(5.58-6.33)$ & $5.92(5.43-6.45)$ & 0.70 & 0.93 \\
\hline$+4 \mathrm{~d}$ & $3.85(3.48-4.26)$ & $3.92(3.57-4.31)$ & $3.86(3.63-4.22)$ & 0.75 & $3.69(3.47-3.92)$ & $4.02(3.68-4.40)$ & 0.11 & 0.50 \\
\hline \multirow{2}{*}{\multicolumn{9}{|c|}{ Maximal insulin concentration ${ }^{3}(\mu \mathrm{IU} / \mathrm{mL})$}} \\
\hline & & & & & & & & \\
\hline$-28 \mathrm{~d}$ & $184(148-227)$ & $147(120-182)$ & $160(130-197)$ & 0.31 & $154(133-180)$ & $172(141-211)$ & 0.37 & 0.69 \\
\hline$-10 \mathrm{~d}$ & $124(103-150)$ & $103(85-124)$ & $110(91-133)$ & 0.34 & $110(96-127)$ & $115(95-139)$ & 0.74 & 0.93 \\
\hline$+4 \mathrm{~d}$ & $57(45-71)$ & $51(41-65)$ & $42(33-53)$ & 0.13 & $54(46-63)$ & $43(34-54)$ & 0.08 & 0.56 \\
\hline \multirow{2}{*}{\multicolumn{9}{|c|}{ Insulin AUC $(\mathrm{mIU} \cdot 120 \mathrm{~min} / \mathrm{mL})^{3}$}} \\
\hline & & & & & & & & \\
\hline$-28 \mathrm{~d}$ & $7.07(5.58-8.97)$ & $6.29(5.07-7.79)$ & $6.19(5.00-7.67)$ & 0.58 & $5.99(5.16-6.94)$ & $7.06(5.73-8.71)$ & 0.19 & 0.65 \\
\hline$-10 \mathrm{~d}$ & $5.15(4.24-6.26)$ & $4.36(3.62-5.26)$ & $4.67(3.87-5.63)$ & 0.49 & $4.47(3.93-5.09)$ & $4.98(4.17-5.94)$ & 0.33 & 0.94 \\
\hline$+4 \mathrm{~d}$ & $1.73(1.42-2.11)$ & $1.44(1.18-1.76)$ & $1.37(1.13-1.67)$ & 0.18 & $1.56(1.34-1.81)$ & $1.46(1.20-1.77)$ & 0.56 & 0.50 \\
\hline$+21 \mathrm{~d}$ & $2.08(1.71-2.54)$ & $1.93(1.60-2.33)$ & $1.75(1.45-2.11)$ & 0.31 & $1.88(1.65-2.15)$ & $1.94(1.63-2.32)$ & 0.74 & 0.35 \\
\hline \multicolumn{9}{|c|}{ Time (min) to half-maximal insulin concentration ${ }^{3}$} \\
\hline$-28 \mathrm{~d}$ & $48.6(42.1-55.2)$ & $49.8(43.2-56.3)$ & $50.9(44.4-57.4)$ & 0.89 & $47.9(43.3-52.5)$ & $51.6(45.6-57.9)$ & 0.25 & 0.38 \\
\hline$-10 \mathrm{~d}$ & $49.4(39.4-59.3)$ & $56.2(46.4-66.1)$ & $54.1(44.2-64.1)$ & 0.51 & $51.4(44.2-58.1)$ & $55.1(45.6-64.6)$ & 0.30 & 0.07 \\
\hline$+4 \mathrm{~d}$ & $29.1(25.0-33.8)$ & $28.7(24.7-33.3)$ & $26.5(22.7-30.9)$ & 0.63 & $28.7(23.2-30.5)$ & $28.7(27.9-33.2)$ & 0.64 & 0.74 \\
\hline$+21 \mathrm{~d}$ & $29.4(25.6-33.1)$ & $29.6(25.9-32.6)$ & $29.3(25.8-32.8)$ & 0.23 & $27.8(25.4-30.5)$ & $28.9(26.4-31.4)$ & 0.48 & 0.48 \\
\hline \multicolumn{9}{|c|}{ Time (min) to maximal insulin concentration } \\
\hline$-28 \mathrm{~d}$ & $12.4(10.3-14.6)$ & $11.5(9.3-13.6)$ & $12.0(9.9-14.1)$ & 0.59 & $10.4(8.9-11-9)$ & $13.5(11.4-15.6)$ & 0.05 & 0.71 \\
\hline$-10 \mathrm{~d}$ & $14.6(11.5-17.6)$ & $12.0(9.0-15.1)$ & $13.9(10.4-17.6)$ & 0.41 & $12.3(9.6-14.9)$ & $14.5(10.9-18.1)$ & 0.08 & 0.74 \\
\hline$+4 \mathrm{~d}$ & $8.1(6.6-9.6)$ & $6.8(5.3-8.2)$ & $7.7(6.2-9.1)$ & 0.32 & $7.3(6.3-8.5)$ & $7.6(6.1-9.1)$ & 0.75 & 0.16 \\
\hline$+21 \mathrm{~d}$ & $7.3(5.3-9.2)$ & $7.4(5.5-9.3)$ & $6.9(5.0-8.7)$ & 0.92 & $7.1(5.7-8.5)$ & $7.3(5.4-9.1)$ & 0.88 & 0.95 \\
\hline \multicolumn{9}{|c|}{ Insulin clearance rate $(\% / \mathrm{min})$} \\
\hline$-28 \mathrm{~d}$ & $2.4(2.0-2.8)$ & $1.9(1.6-2.3)$ & $2.2(1.8-2.6)$ & 0.21 & $2.2(1.9-2.5)$ & $2.0(1.6-2.4)$ & 0.34 & 0.73 \\
\hline$-10 \mathrm{~d}$ & $2.5(2.0-3.0)$ & $1.9(1.4-2.4)$ & $2.3(1.8-2.8)$ & 0.23 & $2.3(1.9-2.7)$ & $2.0(1.4-2.5)$ & 0.15 & 0.31 \\
\hline$+4 \mathrm{~d}$ & $3.8(3.2-4.5)$ & $4.1(3.4-4.7)$ & $4.1(3.4-4.7)$ & 0.81 & $4.4(3.9-4.9)$ & $3.6(2.9-4.2)$ & 0.03 & 0.97 \\
\hline$+21 \mathrm{~d}$ & $4.2(3.6-4.9)$ & $4.5(3.9-5.1)$ & $4.1(3.5-4.7)$ & 0.52 & $4.6(4.1-5.0)$ & $3.9(3.2-4.5)$ & 0.04 & 0.52 \\
\hline
\end{tabular}

${ }^{\mathrm{ac}}$ Means within a row with different superscript letters differ (Tukey post hoc test $P<0.10$ ).

$\delta \quad{ }^{1}$ The interaction between treatment and HYK was tested and retained in the analysis if $P<0.05$. Enrollment block included as a random effect. Results reported as mean or geometric mean and 5. CI Treatments: Controlled-eneroy prepartum diet, fed for ad libitum intake to control intake to $100 \%$ of energy requirements; intermediate-eneroy prepartum diet, fed for ad libitum intake to 6 control intake to $100 \%$ of energy requirements from 57 to $29 \mathrm{~d}$ before expected parturition and approximately $125 \%$ of energy requirements from $28 \mathrm{~d}$ before expected parturition until calving; high-

$z \quad$ energy prepartum diet, fed for ad libitum intake to achieve energy intake at approximately $150 \%$ of requirements.

${ }^{2}$ Hyperketonemia (HYK): animals with a BHB concentration $\geq 1.2 \mathrm{mmol} / \mathrm{L}$ at any time point within the first 21 DIM were considered as hyperketonemic for this analysis.

${ }^{3}$ Geometric mean and $95 \%$ CI for log-transformed data calculated as $\mathrm{e}^{\mathrm{x}}$.

- For the interaction T $\times$ HYK, the least squares means (95\% CI) were 27.4 (24.2-31.1), 31.1 (27.2-35.6), and 26.7 (23.1-30.8) min for the controlled, intermediate, and high group without HYK, and $27.3(22.0-33.9), 28.3(23.6-33.9)$, and $37.9(32.1-44.7)$ min for the same groups in case of HYK, respectively. 
lenge or the ability of adipose tissue to respond to the insulin stimulus.

\section{Resting Concentration of Pancreatic Hormones, Glucose, and Markers of Negative Energy Balance}

Measurement of baseline glucose, NEFA, insulin, glucagon, BHB, and IG ratio was carried out as an alternate assessment of metabolic status pre- and postpartum and revealed notable differences on d 4 postpartum (Figure 4). Prepartum glucose concentrations were higher in cows in group $\mathrm{H}$ compared with both groups I and $\mathrm{C}$ at both prepartum time points [d 28 prepartum: group H: $77.8(74.6-81.1) \mathrm{mg} / \mathrm{dL}$ vs. C: $73.9(70.8-77.1) \mathrm{mg} / \mathrm{dL} ; P=0.07$; and I: $73.4(70.3-$ $76.5) \mathrm{mg} / \mathrm{dL} ; P=0.04$; d 10 prepartum: group $\mathrm{H}: 75.9$ $(73.8-78.1) \mathrm{mg} / \mathrm{dL}$ vs. C: $69.6(67.6-71.7) \mathrm{mg} / \mathrm{dL} ; P=$ 0.004 ; and I: $70.6(68.5-72.7) \mathrm{mg} / \mathrm{dL} ; P=0.008]$. The higher blood glucose concentration in prepartum cows fed a higher energy diet has been observed by others (Schoenberg and Overton, 2011) but could be due to increased propionate conversion in the liver (Janovick et al., 2011). We hypothesize that the higher prepartum plasma glucose concentration in group $\mathrm{H}$ could have been caused by availability of nutrients in the form of starch in excess of requirements, resulting in greater availability of propionate for hepatic gluconeogenesis.
Glucose concentrations were lowest in group $\mathrm{H}[56.0$ (53.4-58.5) mg/dL] and highest in group C [59.9 (57.4$62.4) \mathrm{mg} / \mathrm{dL} ; P=0.08]$ on d 4 postpartum. Baseline values of NEFA increased greatly on d 4 postpartum from prepartum values and were highest in group $\mathrm{H}$ [1.63 (1.52-1.74) mmol/L] compared with both groups C $[1.37(1.26-1.48) \mathrm{mmol} / \mathrm{L} ; P=0.004]$ and I [1.38 $(1.27-1.50) \mathrm{mmol} / \mathrm{L} ; P=0.008]$. This is in accordance with a tendency for a more pronounced negative energy balance in group $\mathrm{H}$ compared with group $\mathrm{C}$ in the postpartum period, which we previously described (Mann et al., 2015). These findings are of particular importance for future reproductive success as low blood glucose concentrations after calving are associated with subfertility due to its role as regulator of hormones (such as insulin and IGF-1) and metabolites (such as NEFA) controlling reproductive function (Garverick et al., 2013; Lucy et al., 2013).

Insulin baseline concentrations decreased from values measured on $\mathrm{d}-28$ to reach the lowest concentration on d 4 postpartum. Insulin baseline values on d 4 postpartum were lowest in group $\mathrm{H}[0.95(0.55-1.62) \mu \mathrm{U} /$ $\mathrm{mL}]$ compared with groups $\mathrm{C}[2.10(1.22-3.58) \mu \mathrm{U} /$ $\mathrm{mL} ; P=0.09]$ and $\mathrm{I}[2.32(1.38-3.92) \mu \mathrm{U} / \mathrm{mL} ; P=$ 0.05]. Baseline glucagon concentrations increased after calving and were different among groups on $\mathrm{d} 4$ postpartum with the highest concentration in group $\mathrm{H}$

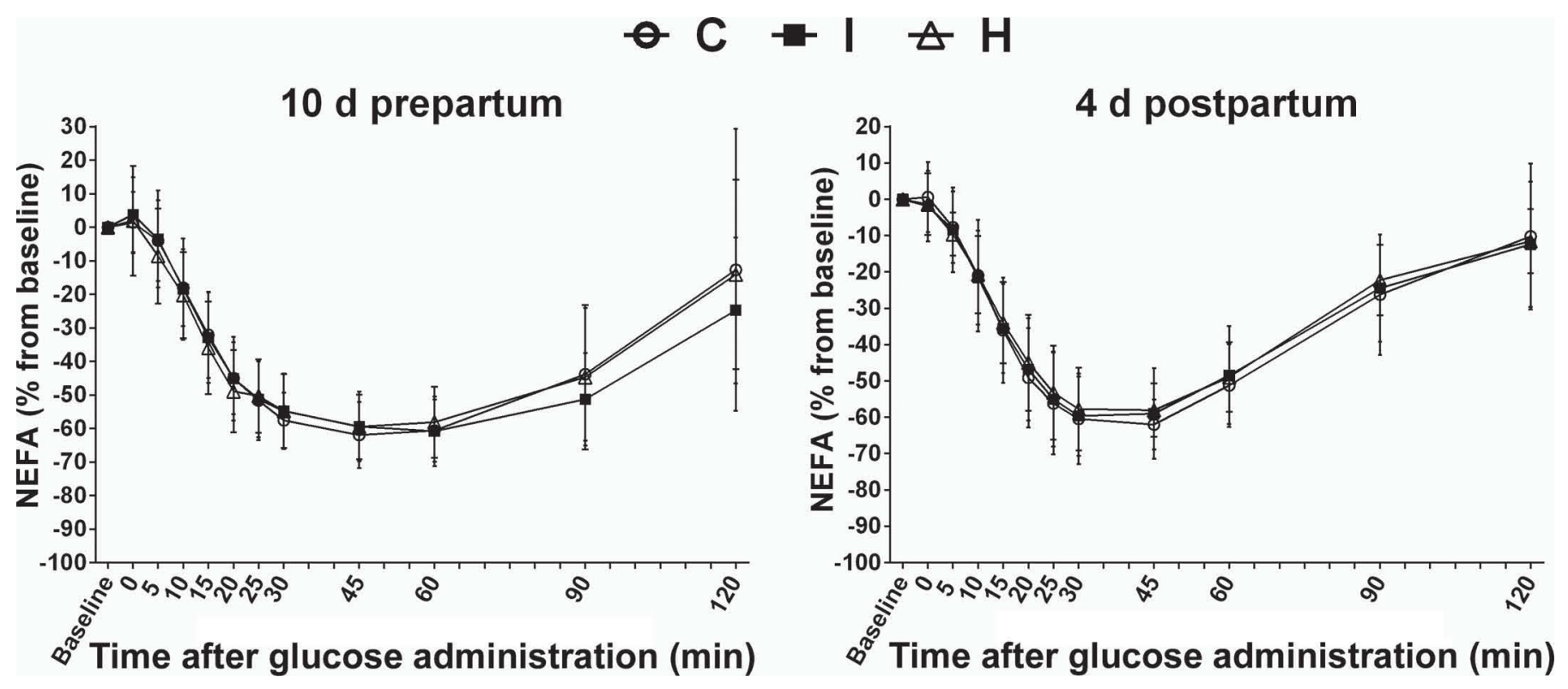

Figure 3. Reduction of nonesterified fatty acid (NEFA) concentration (in \% from baseline) during intravenous glucose tolerance test (IVGTT) $10 \mathrm{~d}$ prepartum as well as $4 \mathrm{~d}$ postpartum. Error bars represent SD and time point 0 the sample taken immediately after intravenous bolus administration of $0.25 \mathrm{~g}$ of glucose per $\mathrm{kg}$ of BW. Baseline represents the average of samples taken 15 and 5 min before glucose infusion. $\mathrm{C}=$ controlled-energy prepartum diet, fed for ad libitum intake to control intake to $100 \%$ of energy requirements; $\mathrm{I}=$ intermediate-energy prepartum diet, fed for ad libitum intake to control intake to $100 \%$ of energy requirements from 57 to 29 d before expected parturition and approximately $125 \%$ of energy requirements from $28 \mathrm{~d}$ before expected parturition until calving; $\mathrm{H}=\mathrm{high}-\mathrm{energy}$ prepartum diet, fed for ad libitum intake to achieve energy intake at approximately $150 \%$ of requirements. Values were based on 19 animals in each group. 

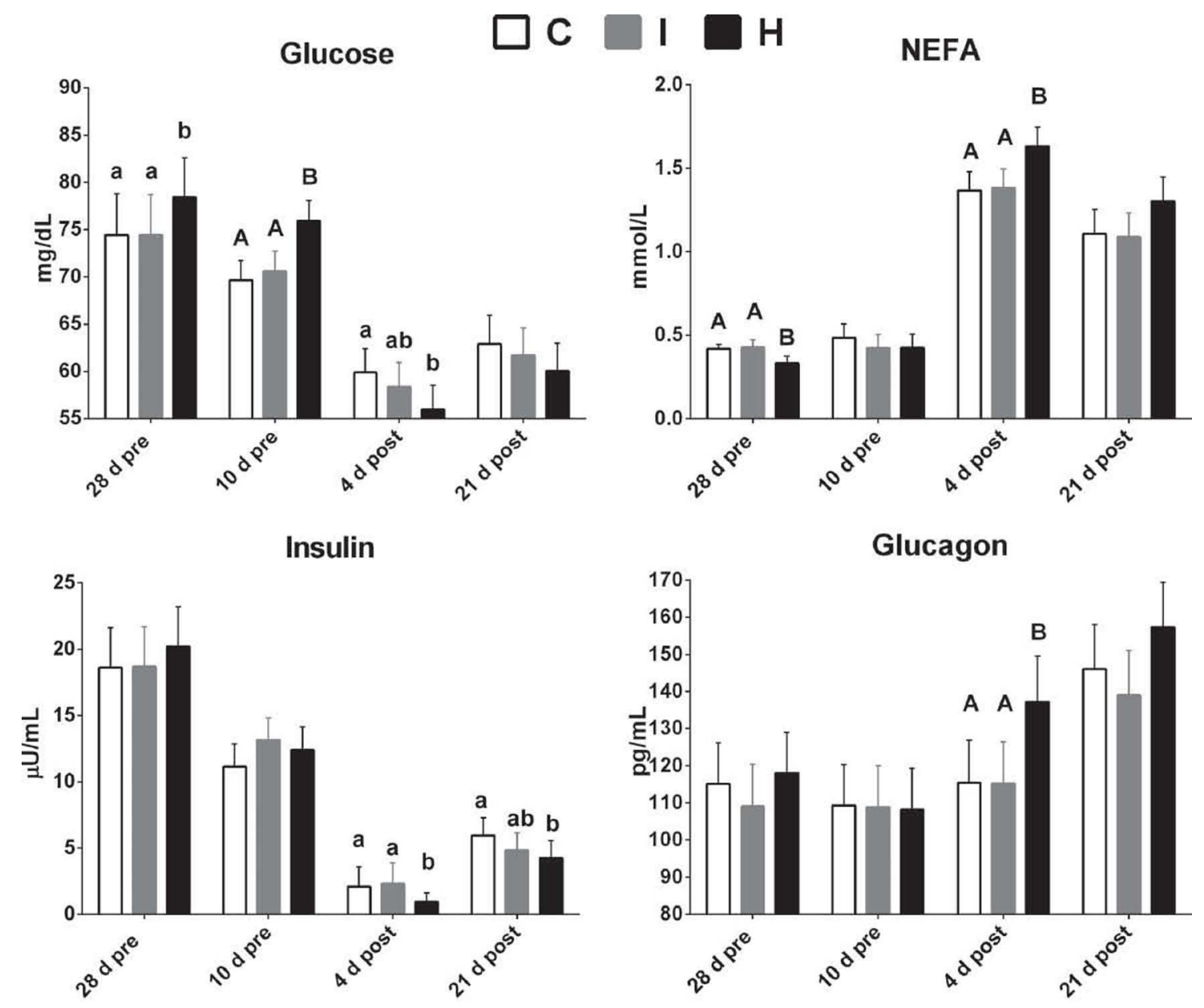

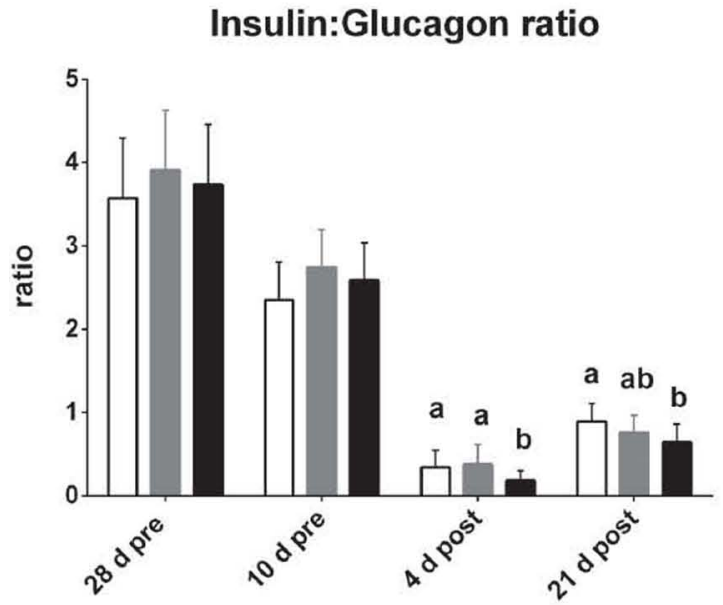

Time relative to calving $(d)$

\section{$\mathrm{BHB}$}

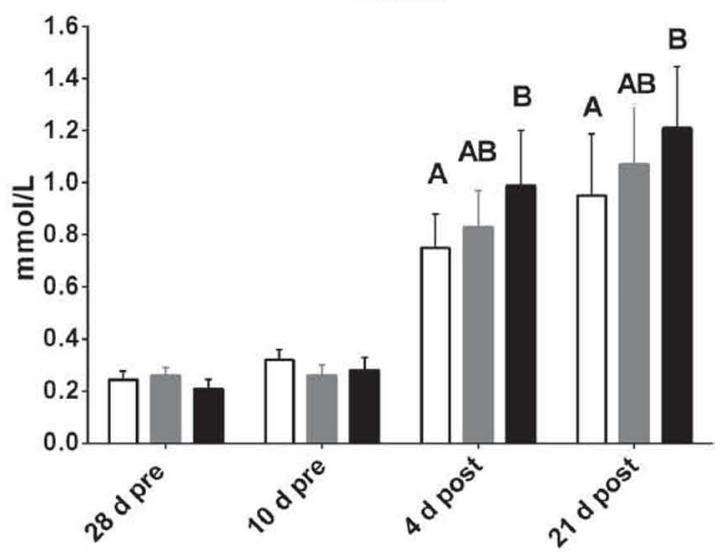

Time relative to calving (d)

Figure 4. Least squares means of baseline concentration of glucose (top left), nonesterified fatty acids (NEFA; top right), insulin (middle left), glucagon (middle right), molar insulin:glucagon ratio (bottom left) and BHB (bottom right) at 28 and $10 \mathrm{~d}$ before expected calving as well as 4 and $21 \mathrm{~d}$ after calving. Error bars represent 95\% CI; enrollment block was included as a random effect. C = controlled-energy prepartum diet, fed for ad libitum intake to control intake to $100 \%$ of energy requirements; I = intermediate-energy prepartum diet, fed for ad libitum intake to control intake to $100 \%$ of energy requirements from 57 to $29 \mathrm{~d}$ before expected parturition and approximately $125 \%$ of energy requirements from $28 \mathrm{~d}$ before expected parturition until calving: $\mathrm{H}=$ high-energy prepartum diet, fed for ad libitum intake to achieve energy intake at approximately $150 \%$ of requirements. Columns marked with different uppercase letters (A, B) are different at a level of $P<0.05$ in ANOVA and Tukey's post hoc test; columns marked with different letters $(\mathrm{a}, \mathrm{b})$ are different at a level of $P<0.10$ ANOVA and Tukey's post hoc test. Values were based on 19 animals in each group except glucose, which was based on 28 animals in each group. 
[137.2 (126.5-149.5) pg/mL] compared with groups C [115.4 (103.8-126.9) pg/mL; $P=0.007]$ and I [117.1 $(105.3-128.8) \mathrm{pg} / \mathrm{mL} ; P=0.009]$. Cows experience a natural decrease in insulin concentration as part of the homeorhetic regulation to enable increased gluconeogenesis and lipolysis (Bell, 1995; Nielsen et al., 2014), whereas glucagon is upregulated at the initiation of lactation (De Koster and Opsomer, 2013) and increases the oxidation of NEFA as well as plasma glucose concentrations (Bobe et al., 2003). The combination of decreased insulin and increased glucagon baseline concentrations allows for increased protein degradation (Rooyackers and Nair, 1997) and increased gluconeogenesis in the liver (Aschenbach et al., 2010). This physiological adaptation to the catabolic period (Holtenius and Holtenius, 1996) was observed in all treatment groups as a response to reduced glucose availability. However, the decrease in insulin and glucose concentrations and increase in glucagon concentration were most pronounced in cows in group $\mathrm{H}$. This was reflected in a lower insulin:glucagon ratio in this group (Figure 4), indicating a more severe negative energy balance, leading to increased ketogenesis during this period when the capacity of gluconeogenesis becomes insufficient to provide energy substrates (Heitmann et al., 1987). This was further supported by the negative relationship of BHB with glucose concentrations on d 4 postpartum ( $\mathrm{r}$ $=-0.53, P<0.0001 ;$ Figure 5). Animals with resting BHB concentrations $\geq 1.2 \mathrm{mmol} / \mathrm{L}$ had lower concentrations of glucose on this day compared with those having BHB concentrations $<1.2 \mathrm{mmol} / \mathrm{L}$ [51.6 (48.6-54.6) vs. $60.2(58.7-61.8) \mathrm{mg} / \mathrm{dL}, P<0.0001]$.

Lower insulin concentrations in cows postpartum have previously been reported in cows overfed energy in the dry period (Janovick et al., 2011). Because glucose orchestrates whole-animal metabolism through its effect on circulating concentrations of insulin and other hormones (Lucy, 2008), these changes were likely caused by the lower postpartum glucose concentrations in the overfed group.

Because no differences were found in DMI, milk production, or lactose yield between these treatment groups (Mann et al., 2015) and based on the data presented here, we suggest that these differences in glucose concentrations were not caused by differences in glucose disposal (either into insulin-dependent tissues or the mammary gland), but rather represent a problem of limited glucose synthesis or availability of glucose precursors, or both, in cows overfed energy during the dry period. Several studies have investigated the effect of overfeeding on markers of hepatic gluconeogenesis in cows fed different energy levels in the dry period. In the study by Rukkwamsuk et al. (1999), gluconeogenic enzyme activity was reduced in the liver of overfed cows

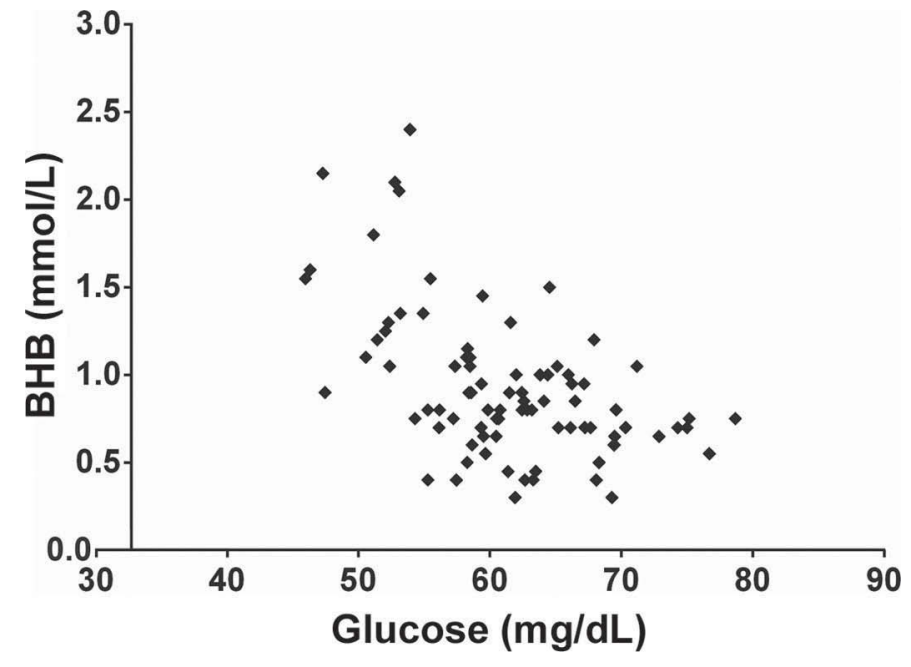

Figure 5. Scatterplot showing the relationship between resting concentrations of blood BHB $(\mathrm{mmol} / \mathrm{L})$ and plasma glucose $(\mathrm{mg} / \mathrm{dL})$ for all cows at d 4 postpartum.

from 1 wk prepartum to 2 wk postpartum. Decreased expression of key enzymes for gluconeogenesis in liver biopsied from $10 \mathrm{~d}$ before parturition until $10 \mathrm{~d}$ after calving were also found in cows overfed energy during the dry period (Selim et al., 2014). In the study by Murondoti et al. (2004), a decreased rate of gluconeogenesis in overfed cows was measured even before development of fatty liver and was thought to be due to a larger amount of ileal-digestible but rumen-undegradable starch. Despite the fact that glucose transporters are present in the whole gastrointestinal tract, only a few feedstuffs such as corn provide enough digestible starch to amount to significant quantities of absorbed glucose, and between 5 to $20 \%$ of consumed starch is digested postruminally (Huntington, 1997; Aschenbach et al., 2010). Therefore, more work is needed to determine if direct absorption of glucose alters regulation of gluconeogenesis in cows overfed energy during the dry period.

\section{Effect of Hyperketonemia on IVGTT Measurements and Baseline Parameters}

A secondary objective was the evaluation of IVGTT and baseline parameters in cows with and without postpartum hyperketonemia. In the first $21 \mathrm{~d}$ postpartum, 7,10 , and 12 animals in groups $\mathrm{C}, \mathrm{I}$, and $\mathrm{H}$, respectively, became hyperketonemic. Complete information of all analytes was available for 20 hyperketonemic and 37 nonhyperketonemic animals. Characteristics of IVGTT for cows with and without postpartum hyperketonemia revealed an increase in glucose AUC, as well as reduced insulin CR postpartum (Table 2). The NEFA AUC on 
d 4 was also not different for HYK versus non-HYK cows $[-60.5(-66.1$ to -54.9$)$ vs. $-65.8(-73.5$ to $-58.2) \mathrm{mmol} \cdot 120 \mathrm{~min} / \mathrm{L} ; P=0.27$ ]. Figure 6 shows the repeated-measures least squares means of resting concentration of glucose, glucagon, insulin, NEFA, and $\mathrm{BHB}$, as well as molar IG ratio from $7 \mathrm{~d}$ prepartum to $7 \mathrm{~d}$ postpartum for cows that did and did not become hyperketonemic. Compared with animals that did not become hyperketonemic, glucose baseline of those animals that did become hyperketonemic within the first 21 DIM was decreased on d 4 [54.5 (51.9-57.0) vs. $60.4(58.7-62.1) \mathrm{mg} / \mathrm{dL} ; P=0.0002]$ and on $\mathrm{d} 21$ postpartum [56.5 (53.8-59.2) vs. $63.9(62.1-65.8) \mathrm{mg} /$ $\mathrm{dL} ; P<0.0001]$. Insulin baseline concentration was also decreased on d 21 postpartum [3.81 (2.57-5.1 $\mu \mathrm{IU} /$ $\mathrm{mL})$ ] compared with nonhyperketonemic animals [5.7 (4.7-6.6) $\mu \mathrm{IU} / \mathrm{mL} ; P=0.02]$ whereas glucagon $[134.7$ $(123.0-146.4)$ vs. $120.0(111.3-128.5) \mathrm{pg} / \mathrm{mL} ; \quad P=$ $0.05]$ and NEFA concentrations [1.6 (1.5-1.7) vs. 1.3 $(1.3-1.4) \mathrm{mmol} / \mathrm{L} ; P=0.01]$ were increased on $\mathrm{d} 4$ postpartum in this group.

In a study by Hove (1978), ketotic cows were characterized by lower insulin response to a glucose challenge and lower glucose concentrations preceding the challenge. Insulin also increased to a smaller degree after feeding in hyperketonemic, hypoglycemic animals compared with nonhyperketonemic animals (Hove and Halse, 1978). In both studies, the authors hypothesized that the decreased secretion of insulin might be caused by the lower secretory capacity of the pancreas developed during the days of lower glucose concentrations in blood preceding the IVGTT and feeding. Sakai et al. (1996) also measured lower blood insulin concentration in ketotic cows after glucose infusion. The decreased insulin concentration allows for lipolysis during hypoglycemia and ketogenesis (Hove, 1974). Prolonged negative energy balance can lead to reductions in pancreatic islet cell and size, lower insulin secretion, hypoinsulinemia, lower glucose concentration, and a lower glucose clearance rate (Hayirli, 2006).

\section{IR Indices and Correlation with IVGTT Parameters}

Surrogate IR indices were evaluated to assess the association with IVGTT parameters. The results and statistical analysis of the calculations for surrogate indices for the treatment groups and hyperketonemia status are shown in Supplementary Table S1 (http:// dx.doi.org/10.3168/jds.2015-9908). We observed no differences in surrogate indices between treatment groups, but indices changed over time, reflecting the changes between time points in glucose, insulin, NEFA, and BHB concentrations as described.
Spearman correlation results between IR indices and IVGTT parameters with $\rho>0.50$ included a positive correlation between NEFA AUC on d 10 prepartum and RQUICKI ( $\rho=0.75, P<0.001)$, as well as RQUICK$\mathrm{I}_{\mathrm{BHB}}(\rho=0.76, P<0.001)$ on the same day. None of the other tested correlations between IR indices and IVGTT parameters yielded a correlation coefficient $>0.50$.

We observed that postpartum BHB concentrations increased from morning blood sampling to those concentrations measured in baseline samples of IVGTT [difference on d 4 postpartum: $0.20(0.15-0.25)$, difference on d 21 postpartum: $0.44(0.36-0.52) \mathrm{mmol} / \mathrm{L}]$. On d 4 postpartum, insulin concentrations in samples obtained during morning blood sampling were, on average, $2.82(2.13-3.51) \mu \mathrm{U} / \mathrm{mL}$ higher than concentrations measured in baseline samples. These differences were not affected by treatment group. Concentration of NEFA on this day increased substantially during this timeframe $[0.65(0.54-0.75) \mathrm{mmol} / \mathrm{L}]$ and increases were different for the 3 treatment groups [C: 0.45 (0.28-0.62), I: $0.68(0.51-0.85)$, H: $0.83(0.66-1.01)$ $\mathrm{mmol} / \mathrm{L} ; P=0.009]$. The correlation between IR indices calculated on d 4 postpartum from samples taken in the morning and those taken on average $5 \mathrm{~h}$ later yielded the following Spearman correlation coefficients: $\rho=0.58$ for HOMA-IR and QUICKI $(P<0.0001), 0.38$ for $\operatorname{RQUICKI}_{\mathrm{BHB}}(P=0.007)$, and 0.37 for RQUICKI $(P=0.008)$. In comparison with the values obtained from the morning samples, HOMA-IR decreased by 0.34 (95\% CI: -0.48 to -0.20 ), QUICKI increased by 0.12 (0.08 to 0.16$)$, RQUICKI increased by 0.05 (0.01 to 0.08$)$, and RQUICKI $\mathrm{BHB}_{\mathrm{BH}}$ increased by $0.03(-0.01$ to 0.06 ). No treatment differences were observed for any of the IR indices on d 4 postpartum from morning samples $(P>0.39)$.

Insulin resistance indices are widely used in human medicine and are interpreted such that increased HOMA-IR and decreased QUICKI indices represent an increase in IR. With the exception of RQUICKI ${ }_{\mathrm{BHB}}$, IR indices in the current study would be interpreted as the highest degree of IR at $28 \mathrm{~d}$ prepartum with the smallest degree of IR on d 4 postpartum. Similar to findings reported by Schulz et al. (2014), we did not measure significant differences between RQUICKI in cows overfed energy in the dry period and those fed a normal control diet. Insulin resistance indices are subject to potential variation caused by stage of lactation and pregnancy (De Koster and Opsomer, 2013), and usefulness in dairy cows is questionable because glucose and insulin kinetics are very different from those in human medicine, where IR indices were established, especially after the onset of lactation (Schoenberg and 


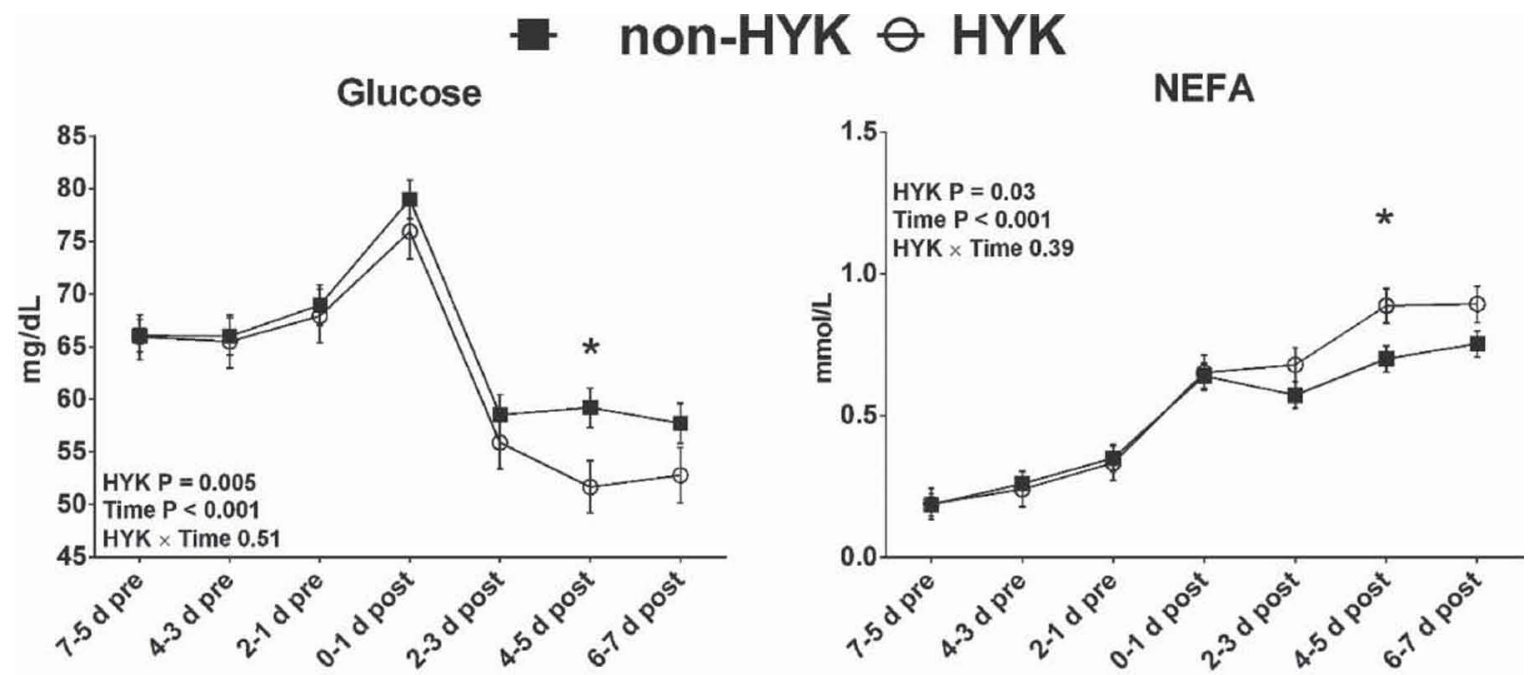

\section{Insulin}
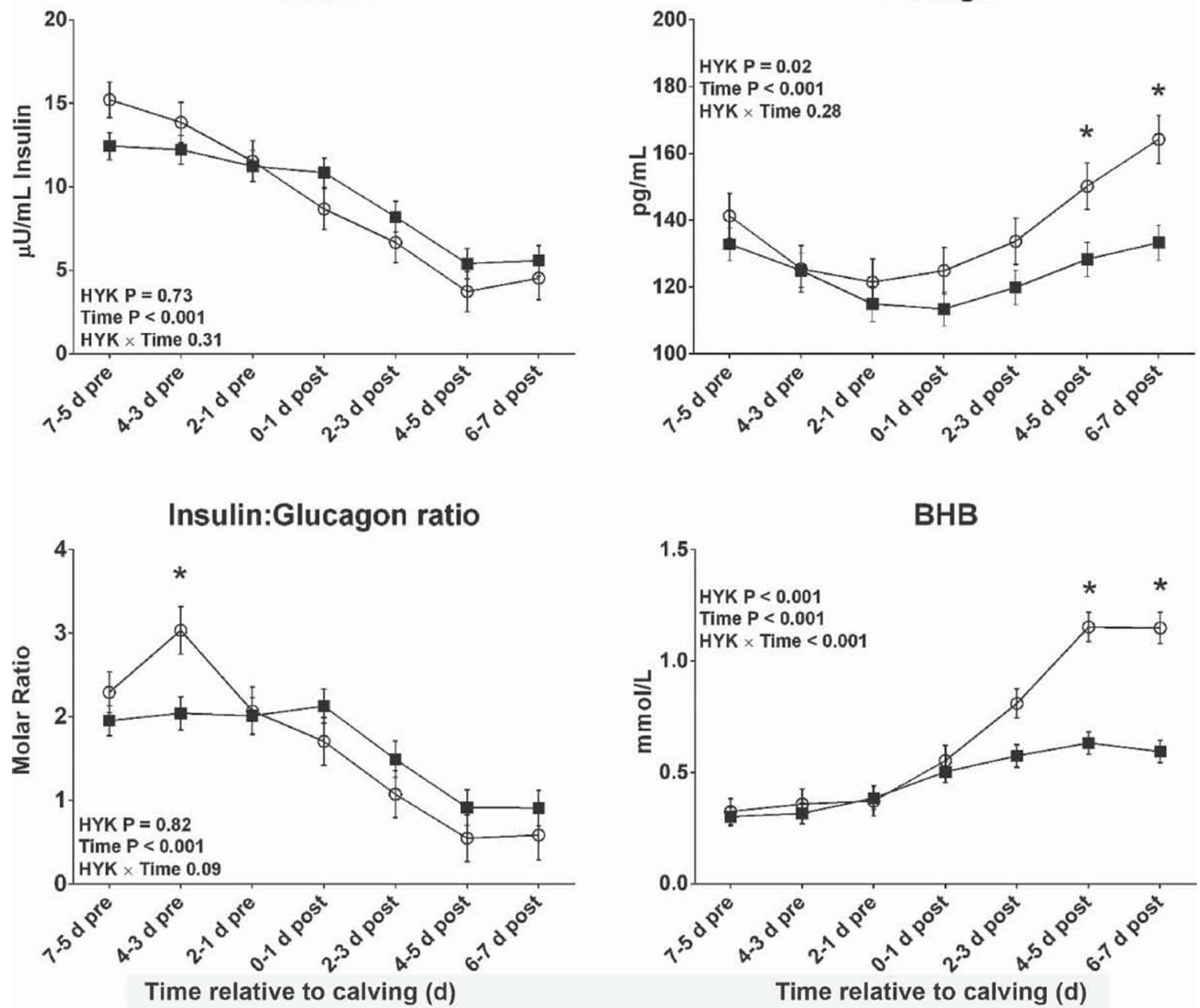

Figure 6. Least squares means of repeated-measures analysis of plasma concentrations of glucose, nonesterified fatty acid (NEFA), insulin, glucagon, molar insulin:glucagon ratio, as well as blood concentration of BHB from d 7 prepartum to d 7 postpartum for animals that became hyperketonemic (HYK; BHB $\geq 1.2 \mathrm{mmol} / \mathrm{L}$ ) or did not in the first 21 DIM. Error bars represent SE. Group differences at a level of $P<0.05$ are marked by an asterisk. Values were based on 20 animals in the hyperketonemic group and 37 animals in the nonhyperketonemic group. $P$-values for fixed effects of HYK, time, and HYK $\times$ time interaction are given. 
Overton, 2011). The poor correlation observed in this study is in accordance with findings by Kerestes et al. (2009). Others have found better correlations between indices and parameters of clamp tests (Haarstrich, 2011), but cows were sampled in mid lactation. An interesting finding of this study was the relatively poor correlation between samples taken at 2 different time points on d 4 postpartum, which can be explained by changes in insulin, NEFA, and BHB over the course of several hours and, in this case, potentially exacerbated by feed deprivation. Differences in measurements can be caused by diurnal changes in metabolites as well as changes induced by a fasted state (Nielsen et al., 2003; Schoenberg et al., 2012), such as an increase in NEFA and decrease in insulin concentrations (Schoenberg and Overton, 2011). It is also possible that increased handling of animals led to a higher degree of stress during IVGTT sampling compared with the morning sampling, which could alter concentrations of certain metabolites such as NEFA (Gupta et al., 2005; Saco et al., 2008).

\section{CONCLUSIONS}

Overfeeding cows during the dry period was not associated with differences in glucose tolerance as assessed by IVGTT in this study, but feeding a high-energy dry-period diet did lead to differences in resting preand postpartum concentrations of glucose, as well as postpartum concentrations of insulin, NEFA, BHB, and glucagon. The usefulness of IR indices in dairy cows is questionable, and values obtained in different stages of lactation and pregnancy should not be compared with each other.

\section{ACKNOWLEDGMENTS}

This project is supported by the Agriculture and Food Research Initiative competitive grant no. 2012-6701530230 and Hatch project NYC-480469 from the USDA National Institute of Food and Agriculture (NIFA; Washington, DC). Any opinions, findings, conclusions, or recommendations expressed in this publication are those of the authors and do not necessarily reflect the view of the NIFA or the USDA. The authors thank Bryant Stuttle, Lauren Stanko Bristol, and Tameeka Williams (Cornell University, Ithaca, NY) for their invaluable assistance with data collection. We greatly acknowledge the assistance of the Endocrinology Laboratory at the Animal Health Diagnostic Center at the Cornell University College of Veterinary Medicine. We also thank the staff at the Cornell University research dairy (Harford, NY).

\section{REFERENCES}

Aschenbach, J. R., N. B. Kristensen, S. S. Donkin, H. M. Hammon, and G. B. Penner. 2010. Gluconeogenesis in dairy cows: The secret of making sweet milk from sour dough. IUBMB Life 62:869-877. http://dx.doi.org/10.1002/iub.400.

Balogh, O., O. Szepes, K. Kovacs, M. Kulcsar, J. Reiczigel, J. A. Alcazar, M. Keresztes, H. Febel, J. Bartyik, S. G. Fekete, L. Fesus, and G. Huszenicza. 2008. Interrelationship of growth hormone AluI polymorphysm, insulin resistance, milk production and reproductive performance in Holstein-Friesian cows. Vet. Med. (Praha) 53:604-616.

Banarer, S., V. P. McGregor, and P. E. Cryer. 2002. Intraislet hyperinsulinemia prevents the glucagon response to hypoglycemia despite an intact autonomic response. Diabetes 51:958-965.

Bell, A. W. 1995. Regulation of organic nutrient metabolism during transition from late pregnancy to early lactation. J. Anim. Sci. 73:2804-2819.

Bobe, G., B. N. Ametaj, J. W. Young, and D. C. Beitz. 2003. Effects of exogenous glucagon on lipids in lipoproteins and liver of lactating dairy cows. J. Dairy Sci. 86:2895-2903. http://dx.doi.org/10.3168/ jds.S0022-0302(03)73886-7.

Bossaert, P., J. L. Leroy, S. De Vliegher, and G. Opsomer. 2008. Interrelations between glucose-induced insulin response, metabolic indicators, and time of first ovulation in high-yielding dairy cows. J. Dairy Sci. 91:3363-3371. http://dx.doi.org/10.3168/jds.2008-0994.

Capurso, C., and A. Capurso. 2012. From excess adiposity to insulin resistance: The role of free fatty acids. Vascul. Pharmacol. 57:9197. http://dx.doi.org/10.1016/j.vph.2012.05.003.

Cardoso, F. C., W. Sears, S. J. LeBlanc, and J. K. Drackley. 2011. Technical note: Comparison of 3 methods for analyzing areas under the curve for glucose and nonesterified fatty acids concentrations following epinephrine challenge in dairy cows. J. Dairy Sci. 94:6111-6115. http://dx.doi.org/10.3168/jds.2011-4627.

Dann, H. M., N. B. Litherland, J. P. Underwood, M. Bionaz, A. D'Angelo, J. W. McFadden, and J. K. Drackley. 2006. Diets during far-off and close-up dry periods affect periparturient metabolism and lactation in multiparous cows. J. Dairy Sci. 89:3563-3577. http://dx.doi.org/10.3168/jds.S0022-0302(06)72396-7.

De Koster, J., M. Hostens, M. Van Eetvelde, K. Hermans, S. Moerman, H. Bogaert, E. Depreester, W. Van den Broeck, and G. Opsomer. 2015. Insulin response of the glucose and fatty acid metabolism in dry dairy cows across a range of body condition scores. J. Dairy Sci. http://dx.doi.org/10.3168/jds.2015-9341.

De Koster, J. D., and G. Opsomer. 2013. Insulin resistance in dairy cows. Vet. Clin. North Am. Food Anim. Pract. 29:299-322. http:// dx.doi.org/10.1016/j.cvfa.2013.04.002.

Debras, E., J. Grizard, E. Aina, S. Tesseraud, C. Champredon, and M. Arnal. 1989. Insulin sensitivity and responsiveness during lactation and dry period in goats. Am. J. Physiol. 256:E295-E302.

Douglas, G. N., T. R. Overton, H. G. Bateman, H. M. Dann, and J. K. Drackley. 2006. Prepartal plane of nutrition, regardless of dietary energy source, affects periparturient metabolism and dry matter intake in Holstein cows. J. Dairy Sci. 89:2141-2157. http://dx.doi. org/10.3168/jds.S0022-0302(06)72285-8.

Drackley, J. K., R. L. Wallace, D. Graugnard, J. Vasquez, B. F. Richards, and J. J. Loor. 2014. Visceral adipose tissue mass in nonlactating dairy cows fed diets differing in energy density. J. Dairy Sci. 97:3420-3430. http://dx.doi.org/10.3168/jds.2014-8014.

Duffield, T. F., K. D. Lissemore, B. W. McBride, and K. E. Leslie. 2009. Impact of hyperketonemia in early lactation dairy cows on health and production. J. Dairy Sci. 92:571-580. http://dx.doi. org/10.3168/jds.2008-1507.

Edmonson, A. J., I. J. Lean, L. D. Weaver, T. Farver, and G. Webster. 1989. A body condition scoring chart for holstein dairy cows. J. Dairy Sci. 72:68-78. http://dx.doi.org/10.3168/jds.S00220302(89)79081-0.

Ferrannini, E., and C. Cobelli. 1987. The kinetics of insulin in man. II. Role of the liver. Diabetes Metab. Rev. 3:365-397.

Garverick, H. A., M. N. Harris, R. Vogel-Bluel, J. D. Sampson, J. Bader, W. R. Lamberson, J. N. Spain, M. C. Lucy, and R. S. 
Youngquist. 2013. Concentrations of nonesterified fatty acids and glucose in blood of periparturient dairy cows are indicative of pregnancy success at first insemination. J. Dairy Sci. 96:181-188. http://dx.doi.org/10.3168/jds.2012-5619.

Gupta, S., B. Earley, S. T. Ting, and M. A. Crowe. 2005. Effect of repeated regrouping and relocation on the physiological, immunological, and hematological variables and performance of steers. J. Anim. Sci. 83:1948-1958.

Haarstrich, D. 2011. Insulin sensitivity and insulin response in lactating dairy cows after a long-term supplementation with conjugated linoleic acids. Doctoral thesis (in German). University of Veterinary Medicine Hannover, Foundation, Germany. Accessed Aug. 25, 2015. http://elib.tiho-hannover.de/dissertations/ haarstrichd_ss11.pdf.

Hayirli, A. 2006. The role of exogenous insulin in the complex of hepatic lipidosis and ketosis associated with insulin resistance phenomenon in postpartum dairy cattle. Vet. Res. Commun. 30:749774. http://dx.doi.org/10.1007/s11259-006-3320-6.

Heinemann, L. 2010. Insulin assay standardization: Leading to measures of insulin sensitivity and secretion for practical clinical care: Response to Staten et al. Diabetes Care 33:e83; author reply e84. http://dx.doi.org/10.2337/dc10-0034.

Heitmann, R. N., D. J. Dawes, and S. C. Sensenig. 1987. Hepatic ketogenesis and peripheral ketone body utilization in the ruminant. J. Nutr. 117:1174-1180.

Holtenius, K., S. Agenas, C. Delavaud, and Y. Chilliard. 2003. Effects of feeding intensity during the dry period. 2. Metabolic and hormonal responses. J. Dairy Sci. 86:883-891. http://dx.doi. org/10.3168/jds.S0022-0302(03)73671-6.

Holtenius, P., and K. Holtenius. 1996. New aspects of ketone bodies in energy metabolism of dairy cows: a review. Zentralbl. Veterinarmed. A 43:579-587.

Hove, K. 1974. Nocturnal plasma insulin levels in cows with varying levels of plasma ketone bodies; relations to plasma sugar and acetoacetate. Acta Endocrinol. (Copenh.) 76:513-524.

Hove, K. 1978. Insulin secretion in lactating cows: Responses to glucose infused intravenously in normal, ketonemic, and starved animals. J. Dairy Sci. 61:1407-1413. http://dx.doi.org/10.3168/jds. S0022-0302(78)83742-4.

Hove, K., and K. Halse. 1978. Absence of feeding-induced variations in plasma insulin in hypoglycaemic-ketonaemic cows. Acta Vet. Scand. 19:215-228.

Huntington, G. B. 1997. Starch utilization by ruminants: From basics to the bunk. J. Anim. Sci. 75:852-867.

Janovick, N. A., Y. R. Boisclair, and J. K. Drackley. 2011. Prepartum dietary energy intake affects metabolism and health during the periparturient period in primiparous and multiparous Holstein cows. J. Dairy Sci. 94:1385-1400. http://dx.doi.org/10.3168/jds.20103303.

Johnson, A. M., and J. M. Olefsky. 2013. The origins and drivers of insulin resistance. Cell 152:673-684. http://dx.doi.org/10.1016/j. cell.2013.01.041.

Katz, A., S. S. Nambi, K. Mather, A. D. Baron, D. A. Follmann, G. Sullivan, and M. J. Quon. 2000. Quantitative insulin sensitivity check index: A simple, accurate method for assessing insulin sensitivity in humans. J. Clin. Endocrinol. Metab. 85:2402-2410. http://dx.doi.org/10.1210/jcem.85.7.6661.

Kerestes, M., V. Faigl, M. Kulcsar, O. Balogh, J. Foldi, H. Febel, Y. Chilliard, and G. Huszenicza. 2009. Periparturient insulin secretion and whole-body insulin responsiveness in dairy cows showing various forms of ketone pattern with or without puerperal metritis. Domest. Anim. Endocrinol. 37:250-261. http://dx.doi. org/10.1016/j.domaniend.2009.07.003.

Khan, M. J., C. B. Jacometo, D. E. Graugnard, M. N. Correa, E. Schmitt, F. Cardoso, and J. J. Loor. 2014. Overfeeding dairy cattle during late-pregnancy alters hepatic PPARalpha-regulated pathways including hepatokines: Impact on metabolism and peripheral insulin sensitivity. Gene Regul. Syst. Bio. 8:97-111. http://dx.doi. org/10.4137/GRSB.S14116

Kronfeld, D. S. 1982. Major metabolic determinants of milk volume, mammary efficiency, and spontaneous ketosis in dairy cows. J.
Dairy Sci. 65:2204-2212. http://dx.doi.org/10.3168/jds.S00220302(82)82483-1.

Lomax, M. A., and G. D. Baird. 1983. Blood flow and nutrient exchange across the liver and gut of the dairy cow. Effects of lactation and fasting. Br. J. Nutr. 49:481-496.

Lucy, M. C. 2008. Functional differences in the growth hormone and insulin-like growth factor axis in cattle and pigs: Implications for post-partum nutrition and reproduction. Reprod. Domest. Anim. 43(Suppl 2):31-39. http://dx.doi.org/10.1111/j.14390531.2008.01140.x.

Lucy, M. C., R. C. Escalante, D. H. Keisler, W. R. Lamberson, and D. J. Mathew. 2013. Short communication: Glucose infusion into early postpartum cows defines an upper physiological set point for blood glucose and causes rapid and reversible changes in blood hormones and metabolites. J. Dairy Sci. 96:5762-5768. http:// dx.doi.org/10.3168/jds.2013-6794.

Malven, P. V., H. H. Head, R. J. Collier, and F. C. Buonomo. 1987. Periparturient changes in secretion and mammary uptake of insulin and in concentrations of insulin and insulin-like growth factors in milk of dairy cows. J. Dairy Sci. 70:2254-2265. http://dx.doi. org/10.3168/jds.S0022-0302(87)80285-0.

Mann, S., F. A. Yepes, T. R. Overton, J. J. Wakshlag, A. L. Lock, C. M. Ryan, and D. V. Nydam. 2015. Dry period plane of energy: Effects on feed intake, energy balance, milk production, and composition in transition dairy cows. J. Dairy Sci. 98:3366-3382. http:// dx.doi.org/10.3168/jds.2014-9024.

McArt, J. A., D. V. Nydam, and G. R. Oetzel. 2013a. Dry period and parturient predictors of early lactation hyperketonemia in dairy cattle. J. Dairy Sci. 96:198-209.

McArt, J. A., D. V. Nydam, G. R. Oetzel, T. R. Overton, and P. A. Ospina. 2013b. Elevated non-esterified fatty acids and betahydroxybutyrate and their association with transition dairy cow performance. Vet. J. 198:560-570. http://dx.doi.org/10.1016/j. tvjl.2013.08.011.

Muniyappa, R., S. Lee, H. Chen, and M. J. Quon. 2008. Current approaches for assessing insulin sensitivity and resistance in vivo: advantages, limitations, and appropriate usage. Am. J. Physiol. Endocrinol. Metab. 294:E15-E26. http://dx.doi.org/10.1152/ ajpendo.00645.2007.

Murondoti, A., R. Jorritsma, A. C. Beynen, T. Wensing, and M. J. Geelen. 2004. Activities of the enzymes of hepatic gluconeogenesis in periparturient dairy cows with induced fatty liver. J. Dairy Res. 71:129-134.

Nielsen, N. I., K. L. Ingvartsen, and T. Larsen. 2003. Diurnal variation and the effect of feed restriction on plasma and milk metabolites in TMR-fed dairy cows. J. Vet. Med. A Physiol. Pathol. Clin. Med. 50:88-97.

Nielsen, T. S., N. Jessen, J. O. Jorgensen, N. Moller, and S. Lund. 2014. Dissecting adipose tissue lipolysis: Molecular regulation and implications for metabolic disease. J. Mol. Endocrinol. 52:R199 R222. http://dx.doi.org/10.1530/JME-13-0277.

Perseghin, G., A. Caumo, M. Caloni, G. Testolin, and L. Luzi. 2001. Incorporation of the fasting plasma FFA concentration into QUICKI improves its association with insulin sensitivity in nonobese individuals. J. Clin. Endocrinol. Metab. 86:4776-4781. http://dx.doi. org/10.1210/jcem.86.10.7902.

Pethick, D. W. 2005. Fat metabolism and turnover. Pages 345-371 in Quantitative Aspects of Ruminant Digestion and Metabolism. 2nd ed. J. Dijkstra, J. M. Forbes, and J. France, ed. CABI, Cambridge, MA.

Rooyackers, O. E., and K. S. Nair. 1997. Hormonal regulation of human muscle protein metabolism. Annu. Rev. Nutr. 17:457-485. http://dx.doi.org/10.1146/annurev.nutr.17.1.457.

Ruan, H., and H. F. Lodish. 2003. Insulin resistance in adipose tissue: Direct and indirect effects of tumor necrosis factor-alpha. Cytokine Growth Factor Rev. 14:447-455.

Rukkwamsuk, T., T. Wensing, and M. J. Geelen. 1999. Effect of fatty liver on hepatic gluconeogenesis in periparturient dairy cows. J. Dairy Sci. 82:500-505. http://dx.doi.org/10.3168/jds.S00220302(99)75260-4. 
Saco, Y., M. Fina, M. Gimenez, R. Pato, J. Piedrafita, and A. Bassols. 2008. Evaluation of serum cortisol, metabolic parameters, acute phase proteins and faecal corticosterone as indicators of stress in cows. Vet. J. 177:439-441. http://dx.doi.org/10.1016/j. tvjl.2007.05.019.

Sakai, T., M. Hamakawa, and S. Kubo. 1996. Glucose and xylitol tolerance tests for ketotic and healthy dairy cows. J. Dairy Sci. 79:372-377. http://dx.doi.org/10.3168/jds.S0022-0302(96)763749.

Schoenberg, K. M., R. M. Ehrhardt, and T. R. Overton. 2012. Effects of plane of nutrition and feed deprivation on insulin responses in dairy cattle during late gestation. J. Dairy Sci. 95:670-682. http:// dx.doi.org/10.3168/jds.2011-4529.

Schoenberg, K. M., and T. R. Overton. 2011. Effects of plane of nutrition and 2,4-thiazolidinedione on insulin responses and adipose tissue gene expression in dairy cattle during late gestation. J. Dairy Sci. 94:6021-6035. http://dx.doi.org/10.3168/jds.2011-4533.

Schulz, K., J. Frahm, U. Meyer, S. Kersten, D. Reiche, J. Rehage, and S. Danicke. 2014. Effects of prepartal body condition score and peripartal energy supply of dairy cows on postpartal lipolysis, energy balance and ketogenesis: An animal model to investigate subclini- cal ketosis. J. Dairy Res. 81:257-266. http://dx.doi.org/10.1017/ S0022029914000107.

Selim, S., T. Kokkonen, J. Taponen, A. Vanhatalo, and K. Elo. 2015. Effect of prepartal ad libitum feeding of grass silage on transcriptional adaptations of the liver and subcutaneous adipose tissue in dairy cows during the periparturient period. J. Dairy Sci. 98:55155528. http://dx.doi.org/10.3168/jds.2014-8986.

Selim, S., S. Salin, J. Taponen, A. Vanhatalo, T. Kokkonen, and K. T. Elo. 2014. Prepartal dietary energy alters transcriptional adaptations of the liver and subcutaneous adipose tissue of dairy cows during the transition period. Physiol. Genomics 46:328-337. http://dx.doi.org/10.1152/physiolgenomics.00115.2013.

Urbaniak, G. C., and S. Plous. 2012. Research Randomizer software. Version 4.0. Accessed Aug. 12, 2012. http://www.randomizer.org/ form.htm.

Zachut, M., H. Honig, S. Striem, Y. Zick, S. Boura-Halfon, and U. Moallem. 2013. Periparturient dairy cows do not exhibit hepatic insulin resistance, yet adipose-specific insulin resistance occurs in cows prone to high weight loss. J. Dairy Sci. 96:5656-5669. http:// dx.doi.org/10.3168/jds.2012-6142. 